\title{
Emulsion Polymerization: Effects of Polymerization Variables on the Properties of Vinyl Acetate Based Emulsion Polymers
}

\author{
Hale Berber Yamak
}

Additional information is available at the end of the chapter

http://dx.doi.org/10.5772/51498

\section{Introduction}

Emulsion polymerization is scientifically, technologically and commercially important reaction. It was developed during the World War II because of the need to replace the latex of natural rubber. The synthetic rubbers were produced through radical copolymerization of styrene and butadiene [1-5]. Today, emulsion polymerization is the large part of a massive global industry. It produces high molecular weight colloidal polymers and no or negligible volatile organic compounds. The reaction medium is usually water and this facilitates agitation and mass transfer, and provides an inherently safe process. Moreover the process is environmentally friendly. Other domains justifying also a big production are that of the versatility of the reaction and the ability to control the properties of the emulsion polymers produced. Because of these unique properties, the industry including waterborne polymers produced by emulsion polymerization continues to expand incrementally. The wide range of the products which include synthetic rubbers, toughened plastics, paints, adhesives, paper coatings, floor polishes, sealants, cement and concrete additives, and nonwoven tissues can be produced by emulsion polymerization. More sophisticated applications are also found in cosmetics, biomaterials and high-tech products.

In the emulsion polymerization products, poly(vinyl acetate) emulsion homopolymer and vinyl acetate based emulsion copolymers have a great importance in industrial aspect as well as scientific aspect. They account for $28 \%$ of the total waterborne synthetic latexes. Poly(vinyl acetate) emulsion homopolymer was the first synthetic polymer latex to be made on a commercial scale [6-9]. Its production is growing steadily in both actual quantities and different applications. The largest volume applications are in the area of coating and adhesive. It offers good durability, availability at low cost, compatibility with other materials, excellent adhesive characteristic, and ability to form continuous film upon drying 
of the emulsions. In addition, vinyl acetate can mostly be copolymerized with ethylene, acrylic esters, versatic ester, or vinyl chloride. So it is possible to overcome some poor properties of the vinyl acetate homopolymer such as weak resistance against alkaline and water, being hydrolysis, and impractical values of glass transition temperature and minimum film forming temperature for many applications by these copolymerizations.

Otherwise, the reaction variables play a determinative role on the emulsion copolymerization reactions and the properties of the resulting copolymers due to the significant differences between the properties of vinyl acetate and other comonomers. The emulsion polymerization of vinyl acetate possesses the rather typical properties in comparison the emulsion polymerizations of the comonomers. Vinyl acetate has high water solubility, a high monomer-polymer swelling ratio, and a high chain transfer constant. Thus, the type of emulsion polymerization process (batch, semi-continuous or continuous) is a very important factor affecting the polymerization mechanism and the final properties of the copolymers. There are also many different variables such as agitation speed, initiator type and concentration, emulsifier type and concentration, feeding policy, feeding rate and temperature. Eventually, the production of vinyl acetate based copolymer latexes in a wide range of molecular, particle-morphological, colloidal, physical and film properties can be possible for use in wide variety of applications by change in molecular structure of the comonomer, copolymer composition and the emulsion polymerization variables.

\section{Emulsion polymerization}

Emulsion polymerization is a complex process in which the radical addition polymerization proceeds in a heterogeneous system. This process involves emulsification of the relatively hydrophobic monomer in water by an oil-in-water emulsifier, followed by the initiation reaction with either a water-soluble or an oil-soluble free radical initiator. At the end of the polymerization, a milky fluid called "latex", "synthetic latex" or "polymer dispersion" is obtained. Latex is defined as "colloidal dispersion of polymer particles in an aqueous medium". The polymer may be organic or inorganic. In general, latexes contain 40-60\% polymer solids and comprise a large population of polymer particles dispersed in the continuous aqueous phase (about $10^{15}$ particles per $\mathrm{mL}$ of latex). The particles are within the size range $10 \mathrm{~nm}$ to $1000 \mathrm{~nm}$ in a diameter and are generally spherical. A typical of particle is composed of 1-10000 macromolecules, and each macromolecule contains about 100-106 monomer units [10-16].

The earliest literature references to produce synthetic latex (the term first referred to the white, sticky sap of the rubber tree) are patents originated from Farbenfabriken Bayer in the years 1909 to 1912 [1-3]. These studies involved polymerization of dien monomers in the form of aqueous emulsions which are stabilized by gelatin, egg white (protein), starch, flour, and blood serum as protective colloids to produce something resembling natural rubber latex. Initiation of polymerization depended on aerial oxygen. But these attempts and other similar studies that followed them were substantially different from what is known today as "emulsion polymerization". In 1929, Dinsmore, who was working for The Goodyear Tire \& 
Rubber Company, was the first to be granted a patent to produce a synthetic rubber in the presence of soap as emulsifying agent [4]. This was followed by addition of a free radical initiator (water- or monomer-soluble peroxides), which led to polymerization of the emulsified monomer [5]. The reasons for regarding it as an "emulsion polymerization" were the addition of soap, presumably added as an emulsifying agent in the first instance, as well as of a protein-aceous protective colloid, and the assuming that polymerization took place in the emulsified monomer droplets. Later, the practice of emulsion polymerization grew rapidly and industrial-scale production started in the mid-1930. The major developments in emulsion polymerization took place around the Second World War as a result of the intensive collaborative efforts between academia, industry and government laboratories. During and after World War II, the production of many types of latex both in homopolymers and copolymers of different composition was achieved by using different monomers such as butadiene, styrene, acrylic esters, acrylonitrile and vinyl acetate. A wide variety of initiating systems were used. Conversions of the polymerization reactions were increased. Later, the works of that period were published in reports and books [7-9,17-18]. Otherwise very few papers on the subject were published in the scientific journals during the period 1910-1945, in comparison with the patents [19-23]. From 1945 to the present, numerous books including the literature of emulsion polymerization, its mechanism, kinetics and formulation, and many other topics related to the emulsion polymerization have been published [10-18, 24-31]. In addition, many conferences on the emulsion polymerization have been organized by different institutes since 1966, and the proceedings/books of them have been published. There are also an excessive number of papers on the emulsion polymerization and related subjects in literature. The number of publications on this subject continues to increase steadily.

Looking at the historical development of the emulsion polymerization, it is seen that the trigger factor in this development was the necessity for synthetic rubber in the wartime. The production of styrene/butadiene rubber (SBR) satisfied this requirement. Today, millions of tons of synthetic latexes are produced by the emulsion polymerization process for use in wide variety of applications. In the synthetic latexes, the most important groups are styrene/butadiene copolymers, vinyl acetate homopolymers and copolymers, and polyacrylates. Other synthetic latexes contain copolymers of ethylene, styrene, vinyl esters, vinyl chloride, vinylidene chloride, acrylonitrile, cloroprene and polyurethane.

Styrene/butadiene latexes account for $37 \%$ of the total waterborne synthetic latexes. They are widely used for tires and molded foam. They mostly consist of $70-75 \%$ butadiene by weight and $30-25 \%$ styrene by weight for use as general-purpose rubbers. Their carboxylated forms contain acrylic, methacrylic, maleic, fumaric or itaconic acid whose carboxylic groups provide stabilization of the polymer particles and a good interaction with fillers and pigments. They are used in carpet-backing and paper-coating applications. Styrene/butadiene ratios are commonly 50/50 and 60/40 (by weight). In these compositions, these copolymers are still rubbery at normal ambient temperatures, and the latex particles readily integrate to form coherent films as the latex dries. Styrene/butadiene copolymers become non-rubbery by increasing the styrene content in the copolymer composition, e.g., 85/15 and 90/10 by weight, 
and are used as organic stiffening and reinforcing fillers. When styrene is replaced by acrylonitrile, elastic and solvent resistant emulsion copolymers are obtained, which are used for dipping goods. Additionally, polychloroprene rubbers obtained by emulsion polymerization offer great resistance to chemicals and atmospheric ozone.

Acrylic latexes include pure acrylics and styrene acrylics, which are about $30 \%$ of produced waterborne synthetic latexes. Acrylic monomers comprise the monomeric alkyl esters of acrylic acid and methacrylic acid, and also their derivatives. The most used acrylic monomers in the emulsion polymerizations are methyl-, ethyl-, butyl- and 2-ethylhexylacrylate, methyl methacrylate, and acrylic- and methacrylic-acid. Homopolymer latexes of these monomers are used as exterior or interior coatings, binder for leather, textiles and paper, and as adhesives, laminates, elastomers, plasticizer and floor polishes. These latexes are stable, have good pigment binding and durability. The copolymerizations of these esters with styrene in an enormous range of accessible copolymer compositions offer almost unlimited opportunities to choose for the glass transition temperature, the minimum film forming temperature, the hydrophilic/hydrophobic properties and morphology design.

Vinyl chloride/vinylidene chloride monomers can be polymerized by emulsion polymerization. Poly(vinyl chloride) (E-PVC) product is mostly applied as the dried form. It is spray-dried and milled to form fine powders ("crumbs") which is mixed with plasticizer to form a plastisol, i.e., dispersion of poly(vinyl chloride) particles in liquid organic media. The plastisol is poured into molds to make rubber dolls, shower curtains, embossed wall coverings and many of other common objects. In packing materials, especially for food packaging, the films of poly(vinylidene chloride) latexes are used, which are highly impermeable for both, oxygen and water vapor.

In both of the large volume and the small volume applications, this variety of emulsion polymers and the widespread use of them are caused by emulsion polymerization which offers many kinetic and technological advantages over other polymerization methods. The dispersion medium is water that provides inexpensive, nonflammable, nontoxic and relatively odorless systems. This polymerization has relative simplicity of the technological process. It is possible to produce high molecular weight polymer at a high reaction rates, and the viscosity of latex is independent of the molecular weight. Thus the producing of high solids content emulsions with low viscosity can be achieved in contrast to solutions of polymers. This method offers better temperature control during polymerization due to more rapid heat transfer in the low viscosity emulsion. There are possibilities of feeding the ingredients at any stage of reaction and the achievement of many copolymerizations that consist of different monomers in wide variety physical properties. The control of undesirable side reactions such as chain transfers, and the range and distribution of particle size can also be obtained. In addition, the dry form of emulsion polymers can be used in many applications as well as the use of latex itself (in wet form). For the formation of dry emulsion polymer, the polymer is isolated by coagulating the latex, filtering off the aqueous medium, and washing the derived crumb. The dried crumbs of polymers may be used as molding resins, or in some cases. Nevertheless, there are some disadvantages of the 
emulsion polymerization. The presence of emulsifiers and other ingredients in the system constitutes unavoidable contamination to the polymer. The separation of the polymer from dispersion medium requires additional operations.

Moreover, many applications of emulsion polymers such as paints, floor polishes, inks, varnishes, carpet backing, paper coatings, and adhesives, lead to the isolation of the polymer by the removal of water. By this way, latex is transformed into a polymer film. The film formation process of latex occurs in three major steps: first, the polymer particles become into close contact with each other by evaporation of water. Second, as more water evaporates, the particles undergo deformation to form a void-free solid structure which is still mechanically weak. Last, fusion occurs between adjacent particles to generate mechanically strong film. In many applications, the key stage is the transition between wet, dispersed polymer and dry film. The application temperature should be above the minimum film forming temperature (MFFT) of the latex which commonly corresponds to the glass transition temperature $\left(\mathrm{T}_{\mathrm{g}}\right)$ of the latex polymer in the presence of water [32].

\subsection{Main ingredients of emulsion polymerization}

A typical emulsion polymerization formulation comprises four basic ingredients: 1) monomer, 2) dispersion medium, 3) emulsifier, 4) initiator. Further auxiliaries, such as chain transfer agents, buffers, acids, bases, anti-aging agents, biocids, etc., can be used. In emulsion polymerization process, a monomer or a mixture of monomers is emulsified in the presence of an aqueous solution of an emulsifier in a suitable container. The monomer is thus present almost entirely as emulsion droplets dispersed in water. The initiator causes the monomer molecules to polymerize within a certain temperature range. When the polymerization is complete, a stable colloidal dispersion of polymer particles in an aqueous medium (the latex) will remain.

\subsubsection{Monomer}

Emulsion polymerization requires free-radical polymerizable monomers which form the structure of the polymer. The major monomers used in emulsion polymerization include butadiene, styrene, acrylonitrile, acrylate ester and methacrylate ester monomers, vinyl acetate, acrylic acid and methacrylic acid, and vinyl chloride. All these monomers have a different structure and, chemical and physical properties which can be considerable influence on the course of emulsion polymerization. The first classification of emulsion polymerization process is done with respect to the nature of monomers studied up to that time. This classification is based on data for the different solubilities of monomers in water and for the different initial rates of polymerization caused by the monomer solubilities in water. According to this classification, monomers are divided into three groups. The first group includes monomers which have good solubility in water such as acrylonitrile (solubility in water $8 \%$ ). The second group includes monomers having 1-3\% solubility in water (methyl methacrylate and other acrylates). The third group includes monomers practically insoluble in water (butadiene, isoprene, styrene, vinyl chloride, etc.) [12]. 


\subsubsection{Dispersion medium}

In emulsion polymerizations, the dispersion medium, for monomer droplets and polymer particles, is generally water as well as liquids other than water. Water is cheap, inert and environmentally friendly. It provides an excellent heat transfer and low viscosity. It also acts as the medium of transfer of monomer from droplets to particles, the locus of initiator decomposition and oligomer formation, the medium of dynamic exchange of emulsifier between the phases, and the solvent for emulsifier, initiator, and other ingredients.

\subsubsection{Emulsifier}

These materials perform many important functions in emulsion polymerizations $[11,13,30]$, such as (i) reducing the interfacial tension between the monomer phase and the water phase so that, with agitation, the monomer is dispersed (or emulsified) in the water phase. (ii) Micelle generating substances. If these substances are used above the critical micelle concentration $(\mathrm{CMC})$, they will form micelles which are ordered clusters of emulsifier molecules, with the oil-soluble part of the molecule oriented toward the center of the cluster and the water-soluble part of the molecule toward the water. (iii) Stabilizing the monomer droplets in an emulsion form. (iv) Serving to solubilize the monomer within emulsifier micelles. (v) Stabilizing the growing latex particles. (vi) Also, stabilizing the particles of the final latex. (vii) Acting to solubilize the polymer. (viii) Serving as the site for the nucleation of particles. (ix) Acting as chain transfer agents or retarders.

Emulsifiers (also referred to as surfactant, soap, dispersing agent, and detergents) are surfaceactive agents. These materials consist of a long-chain hydrophobic (oil-soluble) group (dodecyl, hexadecyl or alkyl-benzene) and a hydrophilic (water-soluble) head group. They are usually classified according to the nature of this head group. This group may be anionic, cationic, zwitterionic or non-ionic [30]. Anionic emulsifiers having negatively charged hydrophilic head group are the sodium, potassium and ammonium salts of higher fatty acids, and sulfonated derivatives of of aliphatic, arylaliphatic, or naphtenic compounds. Sodium lauryl (dodecyl) sulfate, $\left[\mathrm{C}_{12} \mathrm{H}_{25} \mathrm{OSO}_{3}{ }^{-} \mathrm{Na}^{+}\right]$, sodium dodecyl benzene sulfonate, $\left[\mathrm{C}_{12} \mathrm{H}_{25} \mathrm{C}_{6} \mathrm{H}_{4} \mathrm{SO}_{3} \mathrm{Na}^{+}\right]$and sodium dioctyl sulfosuccinate, $\left[\left(\mathrm{C}_{18} \mathrm{H}_{7} \mathrm{COOCH}_{2}\right)_{2} \mathrm{SO}_{3} \mathrm{Na}^{+}\right]$are commonly used in emulsion polymerizations as anionic emulsifiers. Quaternary salts such as acetyl dimethyl benzyl ammonium chloride and hexadecyl trimethyl ammonium bromide may be given examples for cationic emulsifiers. Zwitterionic (amphoteric) emulsifiers can show cationic or anionic properties depending on $\mathrm{pH}$ of the medium. They are mainly alkylamino or alkylimino propionic acids. Non-ionic emulsifiers carry no charge unlike ionic emulsifiers. The most used type of these emulsifiers is that with a head group of ethylene oxide (EO) units. Polyoxyethylenated alkylphenols, polyoxyethylenated straight-chain alcohols and polyoxyethylenated polyoxypropylene glycols (i.e., block copolymers formed from ethylene oxide and propylene oxide) are the most commonly three classes of non-ionic emulsifiers used for emulsion polymerization formulations. Polyoxyethylenated alkylphenol type of emulsifiers includes two main members: nonylphenol polyoxyethylene glycol, [ $\mathrm{C}_{9} \mathrm{H}_{17} \mathrm{C}_{6} \mathrm{H}_{4} \mathrm{O}-\left(\mathrm{CH}_{2} \mathrm{CH}_{2}-\right.$ $\left.\mathrm{O})_{n} \mathrm{H}\right]$, and octylphenol polyoxyethylene glycol, [ $\left.\mathrm{C}_{8} \mathrm{H}_{15} \mathrm{C}_{6} \mathrm{H}_{4} \mathrm{O}-\left(\mathrm{CH}_{2} \mathrm{CH}_{2}-\mathrm{O}\right)_{n} \mathrm{H}\right]$. The number of 
EO units, (n), may be diversified from a few toabout 100 (typically from 1 to 70 EO units), which characterize the distribution of polyEO chain lengths for each specific emulsifier. A typical example for polyoxyethylenated polyoxypropylene glycols is polyethylene oxide-polypropylene oxide-polyethylene oxide triblock copolymer, [H- $\left(\mathrm{OCH}_{2} \mathrm{CH}_{2}\right)_{\mathrm{a}}-\left(\mathrm{OCH}_{3} \mathrm{CH}-\mathrm{CH}_{2}\right) \mathrm{b}-\left(\mathrm{OCH}_{2} \mathrm{CH}_{2}\right)_{\mathrm{a}}$ $\mathrm{OH}]$, in which the polyEO portion constitutes between 10 and $80 \%$ of the copolymer.

In general, the anionic emulsifiers are extensively preferred in many emulsion polymerization systems. They serve as strong particle generators and stabilize the latex particles via electrostatic repulsion mechanism. But latexes stabilized with this type of emulsifiers are often unstable upon addition of electrolytes and in freeze-thaw cycles. Furthermore, these emulsifiers have limited stabilizing effectiveness at high solids (e.g., $>40 \%$ ) and present high water sensitivity. To overcome these problems, non-ionic emulsifiers can be used to nucleate and stabilize the particles in the course of emulsion polymerization. In this case, it is the steric stabilization mechanism that protects the interactive particles from coagulation. In addition, the use of non-ionic types improves the stability of latex product against electrolytes, freeze-thaw cycles, water and high shear rates. As a result of them, in many emulsion polymerization recipes (particularly in industry), mixtures of anionic and non-ionic emulsifiers have been widely used together in a synergistic manner to control the particle size and to impart enhanced colloidal stability [33-35]. The cationic and zwitterionic emulsifiers are used infrequently in emulsion polymerization applications.

Besides all these types of emulsifiers, polymeric and reactive emulsifiers can be used in emulsion polymerizations. Polymeric emulsifiers are often non-ionic water-soluble polymers such as poly(vinyl alcohol), hydroxyethyl cellulose and poly(vinyl pyrrolidone), and called sometimes as a "protective colloid". They are used to increase the particle stability in latexes against coagulation. Reactive emulsifiers ("surfmers"), which have polymerizable reactive group, can copolymerize with the main monomer and be covalently anchored onto the surface of latex particles. When these compounds used in emulsion polymerizations, the emulsifier migration is reduced. Furthermore, surfmers improve the water resistance and surface adhesion as well as resistance against electrolytes and freeze-thaw cycles in comparison to conventional emulsifiers. Surfmers can be anionic with sulfate or sulfonate head groups (sodium dodecyl allyl sulfosuccinate), cationic (alkyl maleate trimethylamino ethyl bromide), or non-ionic (functionalized poly(ethylene oxide)-poly(butylenes oxide)copolymer). The reactive groups can be in different types, for example, allylics, acrylamides, (meth)acrylates, styrenics, or maleates [36-37].

\subsubsection{Initiator}

Emulsion polymerization occurs almost entirely following the radical mechanism. The function of the initiator is to generate free radicals, which in turn lead to the propagation of the polymer molecules. The free radicals can be commonly produced by two main ways: (i) thermal decomposition, or (ii) redox reactions. In addition, the free-radical initiators can be either water or oil-soluble. 
The most commonly used water-soluble initiators are persulfates (peroxodisulfates). For example, potassium-, sodium-, and ammonium-persulfate. Persulfate ion decomposes thermally in the aqueous phase to give two sulfate radical anions which can initiate the polymerization. Hydrogen peroxide and other peroxides are thermal decomposition type initiators and they are soluble in both the aqueous and monomer-swolen polymer phases. Besides of these, oil-soluble compounds such as benzoyl peroxide and azobisisobutyronitrile (AIBN) can be employed as thermal initiators in emulsion polymerizations. The other initiation system consists of redox initiators (such as persulfate-bisulfite system) which produce free radicals through an oxidation-reduction reaction at relatively low temperatures.

The main types of free radicals which are produced by thermally or redox system are:

a. Persulfates

$$
\mathrm{S}_{2} \mathrm{O}_{8}^{-2} \rightarrow \mathrm{SO}_{4} \bullet^{-1}+\mathrm{SO}_{4} \bullet^{-1}
$$

b. Hydrogen peroxide

$$
\mathrm{HO}-\mathrm{OH} \rightarrow \mathrm{HO} \bullet+\mathrm{HO} \bullet
$$

c. Organic peroxides

$$
R O-O R^{l} \rightarrow R O \bullet+R^{l} O \bullet
$$

d. Azo compound

$$
R N=N R^{l} \rightarrow R \bullet+R^{l} \bullet+N_{2}
$$

e. Persulfate-Bisulfite

$$
\mathrm{S}_{2} \mathrm{O}_{8}^{-2}+\mathrm{HSO}_{3}^{-1} \rightarrow \mathrm{SO}_{4} \bullet^{-1}+\mathrm{SO}_{3} \bullet^{-1}+\mathrm{HSO}_{4}^{-1}
$$

There is also surface active initiators which are called as "inisurfs", for example; bis[2-(4'sulfophenyl)alkyl]-2,2'-azodiisobutyrate ammonium salts and 2,2'-azobis(N-2'methylpropanoyl-2-amino-alkyl-1-sulfonate)s. The initiators of this type carry stabilizing groups in their structures, and emulsion polymerization can be successfully carried out in the presence of them, without additional stabilizers up to more than $50 \%$ in solid content [37]. Moreover, the free radicals needed to initiate the emulsion polymerization can be produced by ultrasonically, or radiation-induced. ${ }^{60} \mathrm{Co} \gamma$ radiation is the most widely used as radiation-induced initiation system in the emulsion polymerizations.

\subsubsection{Other ingredients}

The formulations of emulsion polymerization may include a wide variety of ingredients: chain transfer agents: are added to a latex formulation to help regulate the molar mass and molar mass distribution of the latex polymer. The mercaptans are the most common type of chain transfer agents. The surface active transfer agents, "transurfs", are also used in 
emulsion polymerizations. Buffers: are often added to a latex formulation to regulate the $\mathrm{pH}$ of the polymerization system. Generally, for this purpose, sodium bicarbonate has been chosen. In addition, coalescing aids, plasticizers, thickening agents, antimicrobial agents, antioxidants, UV-absorbers, pigments, fillers, and other additives can take place in a recipe of emulsion polymerization.

\subsection{Kinetic and mechanism of emulsion polymerization}

Emulsion polymerization is a type of free-radical addition polymerization. Such reactions are comprised of three principal steps, namely initiation, propagation and termination. In the first stage an initiator is used to produce free-radicals which react with monomer containing unsaturated carbon-carbon bonds (its general structure; $\mathrm{CH}_{2}=\mathrm{CR}^{1} \mathrm{R}^{2}$, where $\mathrm{R}^{1}$ and $R^{2}$ are two substituent groups) to initiate the polymerization. When the radical reacts with a monomer molecule a larger free-radical (active center) is formed which, in turn, reacts with another monomer molecule, thus propagating the polymer chain. Growing polymer chains are finally terminated (free electrons coupled) with another free radical, or with chain transfer agents, inhibitors, etc.

The three stages of the free-radical polymerization are shown in the following steps:

Initiation: The reaction of initiation can be described as a two-stage process. In the first stage the initiator is decomposed to free-radicals, in the second stage the primary radicals react with the monomer, converting it to a growing radical.

The first stage where free-radicals can be generated by two principal processes: (1) homolytic scission (i.e. homolysis) of a single bond which can be achieved by the action of heat or radiation, and (2) chemical reaction involving electron transfer mechanism (redox reactions).

The most common method used in emulsion polymerizations is thermal initiation in which the initiator $(I)$ dissociates homolytically to generate a pair of free-radicals $(\mathrm{R} \bullet)$ as shown below:

$$
I \stackrel{k_{d}}{\longrightarrow} 2 R \bullet
$$

where $\mathrm{k}_{\mathrm{d}}$ is the rate constant for the initiator dissociation. The rate of this dissociation, $R_{d}$, is given by,

$$
R_{d}=2 f k_{d}[I]
$$

where $[I]$ is the concentration of the initiator and $f$ is the initiator efficiency. The initiator efficiency is the fraction of primary free radicals $(\mathrm{R} \bullet)$ which are successful in initiating polymerization, and is in the range 0.3-0.8 due to wastage reactions. The factor of 2 enters because two primary free radicals are formed from each molecule of initiator.

In the second stage, the free radicals generated from the initiator system attack the first monomer $(\mathrm{M})$ molecule to initiate chain growth: 


$$
R \bullet+M \stackrel{k_{i}}{\longrightarrow} R M \bullet
$$

where $\mathrm{k}_{\mathrm{i}}$ is the rate constant for the initiation. The rate of initiation, $R_{i}$, is equal to the rate of dissociation of an initiator. Because the primary radical adds to monomer is much faster than the first stage, and so the dissociation of the initiator is the rate-determining step in the initiation sequence. According to this, $R_{i}$ is given by

$$
R_{i}=2 f k_{d}[I]
$$

Propagation: The propagation step is only one which produces polymer. This involves essentially the addition of a large number of monomer molecules $(n)$ to the active centers $(R M \bullet)$ for the growth of polymer chain as shown below.

$$
R M \bullet+n M \stackrel{k_{p}}{\longrightarrow} P_{n+1} \bullet
$$

where $\mathrm{k}_{\mathrm{p}}$ is the rate constant for propagation.

The rate of polymerization, $R_{p}$, is known as the rate of monomer consumption. Monomer is consumed by the propagation reactions as well as by the initiation reaction. The corresponding rate of polymerization is then:

$$
R_{p}=-\frac{d[M]}{d t}=k_{i}[R \bullet][M]+k_{p}[M \bullet][M]
$$

where $[R \bullet]$ is the primary free-radicals concentration, $[\mathrm{M}]$ is the monomer concentration and $[\mathrm{M} \bullet]$ is the total concentration of every size of chain radicals. The amount of monomer consumed in the initiation step can be neglected due to the number of monomer molecules reacting in the initiation step is far less than the number in the propagation step for a process producing high polymer, and a very close approximation of the polymerization rate can be given simply by the rate of propagation. Then, the polymerization rate can be writen:

$$
R_{p}=k_{p}[M \bullet][M]
$$

Termination: In last step of the polymerization, the growing polymer chain is terminated. There are two main mechanisms, recombination and disproportionation, for termination reactions. In these mechanisms, the growing polymer chain react with another growing chain or another free radical of some kind.

Recombination;

$$
P_{n} \bullet+P_{m} \bullet \stackrel{k_{t c}}{\longrightarrow} P_{n+m}
$$

in which two growing chains constitute the coupling with each other resulting in a single polymer molecule. 
Disproportionation;

$$
P_{n} \bullet+P_{m} \bullet \stackrel{k_{t d}}{\longrightarrow} P_{n}+P_{m}
$$

in which one growing chain abstracts a hydrogen atom from another, leaving it with an unsaturated end-group. This mechanism occurs more rarely than recombination. It results in the formation of two polymer molecules, one saturated and one unsaturated. In the above equations, $k_{t c}$ and $k_{t d}$ are the rate constants for termination by recombination and disproportionation, respectively. The overall rate constant for termination reaction is given as $\mathrm{k}_{\mathrm{t}}=\mathrm{k}_{\mathrm{tc}}+\mathrm{k}_{\mathrm{td}}$.

In addition to these main termination reactions, there are some other reactions which can terminate the growing chain radical. These reactions can be occurred by removal of an atom from some substances present in the reaction mixture to give a new radical which may or may not start another chain (chain transfer reactions), or by addition to some substance (such as retarder or inhibitor) into the reaction mixture to give a new radical having little or no ability to continue the propagation of the chain [10].

In the chain transfer reactions, some substances such as polymer, monomer, solvent, additives, impurities, or initiator can act as a chain transfer agent. An example of these reactions is given:

$$
P_{n} \bullet+T-A \longrightarrow P_{n} T+A \bullet
$$

where $T-A$ is a chain transfer agent. The chain radical abstracts $T \bullet$ (often a hydrogen or halogen atom) from $T-A$ molecule to yield a terminate polymer molecule and a new free radical, $A \bullet$ which can initiate a new chain. The main effect of chain transfer is to reduce the molecular weight of the polymer. If the new radical $A \bullet$ is as reactive as the primary radicals, $R \bullet$, there will be no effect on the rate of polymerization.

In polymerization kinetic, steady state conditions must obtain, i.e. where the rate of generation of free radicals (initiation) is equal to the rate at which they disappear (termination). This implies a constant overall concentration of propagating free radicals, $[M \bullet]$. The equation for the steady state conditions is:

$$
R_{i}=R_{t}=-\frac{d[R \bullet]}{d t}=2 k_{t}[M \bullet]^{2}
$$

In practice, most free-radical polymerizations operate under steady state conditions after an induction period wich may be at most a few seconds. When Equation 2.16 is rearranged,

$$
[M \bullet]=\left(\frac{R_{i}}{2 k_{t}}\right)^{1 / 2}
$$

and a general expression for the rate of polymerization can be obtained by combining Equation 2.12 and 2.17, 


$$
R_{p}=k_{p}[M]\left(\frac{R_{i}}{2 k_{t}}\right)^{1 / 2}
$$

This equation show that the polymerization rate depends on the square root of the initiation rate. If we make an arrangement on this equation by using Equation 2.9, we can say that the polymerization rate depends on the square root of the initiator concentration:

$$
R_{p}=k_{p}[M]\left(\frac{f k_{d}[I]}{k_{t}}\right)^{1 / 2}
$$

In the emulsion polymerizations, the free-radical mechanism is very closely connected with the heterogeneous nature of the emulsion polymerization in which the micellar phase, the aqueous phase, the monomer droplet phase and the particle phase exist. Therefore, a number of mechanisms have been proposed for latex particle formation. The most important qualitative mechanism of emulsion polymerization was proposed by Harkins in 1945 and 1946 [38-39]. The following main premises of this mechanism were taken by Smith and Ewart. They managed to obtain first quantitative theory, which consist of equations for determining the rate of polymerization and the number of latex particles, for emulsion polymerization [40]. These theories have been applied only to the emulsion polymerization of "hydrophobic monomers" (such as sytrene) in the presence of water-soluble initiators and nonspecific, micelle-forming emulsifiers at concentrations significantly exceeding the critical micelle concentration. A schematic representation of the Harkins theory is illustrated in Figure 1 [11,41]. Such a system contains the emulsified monomer droplets (ca. 1-10 $\mu \mathrm{m}$ in diameter) dispersed in the continuous aqueous phase with the aid of an emulsifier at the very beginning of polymerization. Monomer-swollen micelles (5-10 $\mathrm{nm}$ in diameter) also exist in this system provided that the concentration of emulsifier in the aqueous phase is above (CMC). Only a small fraction (approximately 1\%) of the total monomer is actually solubilized by the micelles and only an insignificant amount of monomer (with hydrophobic monomers such as styrene; about $0.04 \%$ ) is dissolved by water. Most of the monomer molecules are in the monomer droplets which act as a reservoir of monomers during polymerization. Thus, the system prior to initiation contains mainly three parts: the water phase, large monomer droplets dispersed throughout the water phase, and the emulsifier micelles containing solubilized monomer. In addition, a very small amount of molecularly dissolved emulsifier and monomer-free micelles may exist (Figure 1.a).

After the emulsion of the monomer phase in the water phase and the presence of the emulsifier micelles established, the polymerization is initiated by the addition of initiator. According to the theories proposed by Harkins and Smith and Ewart, conventional emulsion polymerization mechanism occurs into three intervals including the initial (particle formation or nucleation) stage, the particle growth stage and the completion stage.

The initial stage (Interval I): This stage is also called as "particle formation" or "nucleation". With the addition of initiator to the reaction mixture, the free-radicals which initiate the polymerization are generated in the aqueous phase and diffuse into monomer-swollen 
micelles. These micelles are the principal locus for the initiation of polymer particle nuclei. In other words, they act as a meeting place for the hydrophobic monomer and the watersoluble initiator. Since they exhibit an extremely large oil-water interfacial area for diffusing of free-radicals and have high monomer concentration. On the other hand, a small amount of particle initiation can occur within the continuous aqueous phase. Monomer molecules dissolved in this phase are first polymerized by waterborne free-radicals. This would result in the increased hdrophobicity of oligomeric radicals. When a critical chain length is achieved, these oligomeric radicals become so hydrophobic that they show a strong tendency to enter the monomer-swollen micelles and then continue to propagate by reacting with those monomer molecules. But this nucleation becomes less significant as the amount of micellar emulsifier in the system increases. The amount of polymerization occurring in the monomer droplets is regarded as being a very minor proportion of the whole because of their small surface area for diffusing of the free-radicals. As a result, monomer-swollen micelles are favored as the sites of the nucleation of polymer particles. Therefore, this nucleation mechanism, proposed by Harkins and Smith and Ewart and modified by Gardon, is called as "micellar" or "heterogeneous" nucleation [42].

After nucleation, monomer-swollen micelles are transformed into polymer particles swollen with monomer. The monomers are then acquired to the particles continuously from monomer droplets by diffusion through the aqueous phase, because monomer has been consumed with in the reaction loci by the polymerization process. Thus, the micelles grow from tiny groups of emulsifier and monomer molecules to larger groups of polymer molecules held in emulsion by the action of the emulsifier molecules located on the exterior surfaces of the particles. This action of the emulsifiers for providing colloidal stability of the growing particle nuclei occurs by emulsifiers supplied from the aqueous phase; this in turn tends to leads to dissociation of micelles containing monomer in which polymerization has not yet started. With the continued adsorption of micellar emulsifiers on to growing particles, the micelles start to disappear (Figure 1.b). The particle nucleation stage (Interval I) ends with this disappearance of the micelles at relatively early in the reaction (e.g. between $10 \%$ and $20 \%$ conversion). During Interval $\mathrm{I}$, the rate of polymerization increases with the increasing time of reaction and only one out of every 100-1000 micelles becomes a polymer particle. The number of particles nucleated per unit volume of water $\left(N_{p}\right)$ is proportional to the emulsifier concentration and initiator concentration to the 0.6 and 0.4 powers, respectively according to the Smith-Ewart theory. After the particle nucleation process is completed, this number remains relatively constant toward the end of polymerization.

The particle growth stage (Interval II): After the particle nucleation process is completed, polymerization proceeds homogeneously in the polymer particles as the monomer concentration in the particles is maintained at a constant concentration by diffusion of monomer from the monomer droplets. The rate of polymerization in this stage is constant. In addition, during this stage, the number of monomer-swollen polymer particles and the monomer/polymer ratio remain constant. The monomer droplets decrease in size as the size of the polymeric particles increase. When monomer droplets completely disappear in the 
polymerization system (at 50-80\% conversion), the particle growth stage (Interval II) ends (Figure 1.c). In this situation, the polymer particles contain all the unreacted monomer and essentially all of the emulsifier molecules are also attached to the surface of polymer particles.

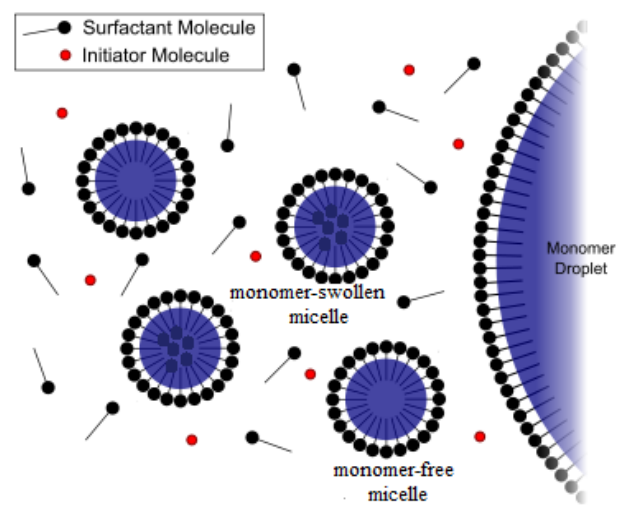

(a)

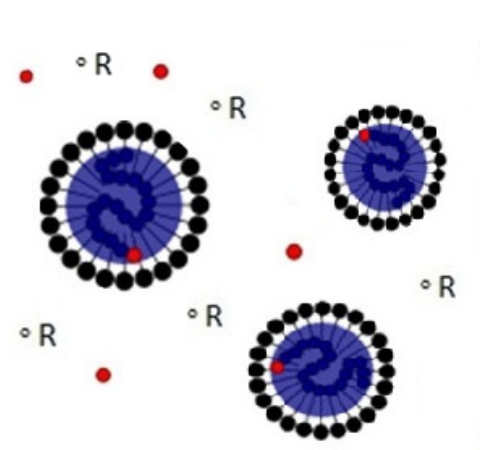

(c)

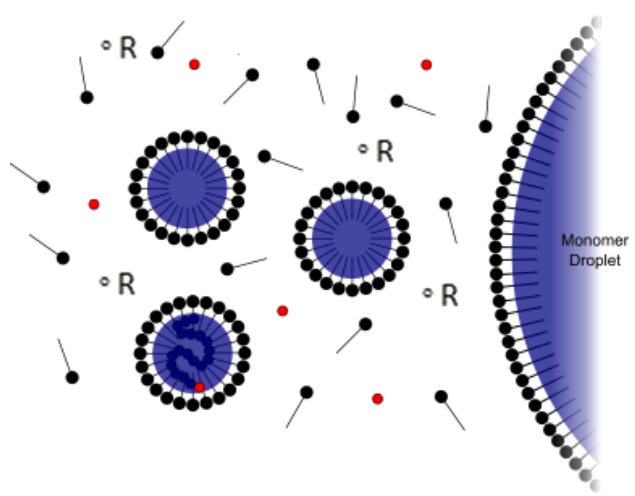

(b)

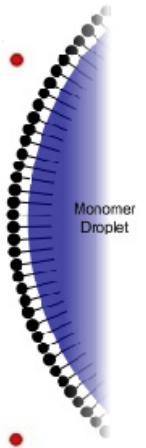

$\circ R$

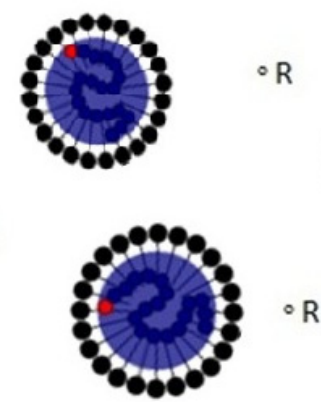

(d)

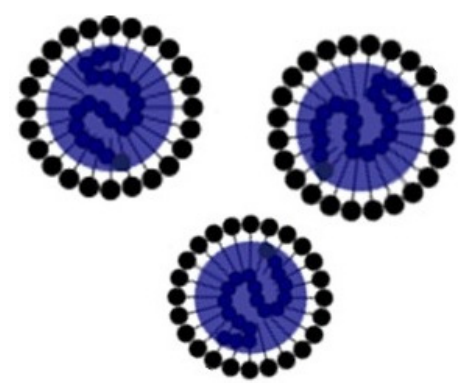

(e)

Figure 1. Schematic representation for the mechanism of emulsion polymerization [11,41] 
The completion stage (Interval III): This is the final stage of the reaction. In this stage, polymerization continues within the monomer-swollen polymer particles which were formed during Interval I, and persisted and grew during Interval II (Figure 1.d). In the ideal case, the number of reaction loci during this stage is essentially fixed at the number which had become formed at the end of Interval I. Whereas, the concentration of monomer in the reaction loci and the polymerization rate continues to decrease toward the end of polymerization. Finally, the polymerization is complete and the conversion of essentially $100 \%$ is usually achieved. The system now comprises a dispersion of small polymer particles stabilized with the molecules of the original emulsifiers (Figure 1.e).

To calculate the rate of emulsion polymerization $\left(R_{p}\right)$ of relatively water-insoluble monomers such as styrene and butadiene, Smith Ewart case 2 kinetics has been widely used [40]:

$$
R_{p}=k_{p}[M]_{p}\left(n N_{p} / N_{A}\right)
$$

where $k_{p}$ is the rate constant of propagation, $\left[M_{p}\right]$ the concentration of monomer in the particles, $n$ the average number of free radicals per particle, and $N_{A}$ the Avogadro number.

Other than micellar nucleation, many mechanisms have been proposed to explain the particle nucleation stage. The best-known alternative theory for particle nucleation is that of "homogeneous nucleation" which includes the formation of particle nuclei in the continuous aqueous phase. This theory is proposed by Priest, Roe and Fitch and Tsai, and extended by Hansen and Ugelstad (HUFT) describes the emulsion polymerization of watersolubble monomers such as vinyl acetate and acrylonitrile, their water solubility though low $(<3 \%)$ is much in excess of the amount of monomer which may be solubilized by the emulsifier [43-48]. It is also the only mechanism which can apply to monomers of low watersolubility, such as styrene, in emulsifier-free reaction system, and also in reaction system which contain a micellizing emulsifier but at such a concentration that is below the CMC. When the monomers are somewhat soluble in the continuous phase, emulsifier micelles have little influence on particle formation. Emulsifier may be required, however, to ensure colloidal stability of the product as it is formed and subsequently "on the shell".

Initially, free-radicals are generated in the aqueous phase by the thermal decomposition of initiator and they can grow by polymerization with those monomer molecules dissolved in the aqueous phase. When a growing oligomer reaches to critical chain lengths, it becomes water-insoluble. The water-insoluble radical then collapses upon itself and becomes effectively a separate phase. The primary particles thus formed provide a potential reaction locus which has within it an active growing free-radical if monomer molecules are available. Replenishment of monomer to the particles takes place by diffusing from the monomer droplets through the continuous phase. Indeed, the collapsed growing oligomer can be regarded as being similar to a emulsifier micelle. The oligomer is to some extent surfaceactive, because it incorporates both a hydrophilic moiety derived from the water-soluble initiator and hydrophobic units derived from the monomer molecules. The particles also 
may grow by limited coagulation of the relatively unstable primary particles [48-49]. The coagulation of these particles can occur with already-existing particles or other primary particles in the earliest (the first few tens of seconds) stage of the reaction. The particles formed by coagulation are now a potential reaction locus where the polymerization continues in the presence of further free-radical as well as monomer molecules. Colloidal stability of the collapsed oligomers and the growing particles is regulated by the amount of emulsifier adsorbed on their surfaces as well as by any other stabilizing group, ionic or nonionic, introduced by functional comonomers, initiator fragments or by chain transfer to molecules. The emulsifiers come from those dissolved in the aqueous phase and those adsorbed on the monomer droplet surfaces. If emulsifier micelles are present, then these are regarded as reservoirs of emulsifier molecules, dissociating as required to provide stabilizer.

The basic principle of this nucleation theory is that the formation of primary particles takes place up to the point where the rate of formation of the radicals in the aqueous phase is equal to the rate of their disappearing via capture of radicals by swollen micelles-if presentinitially and by particles already formed (Figure 2, [14]), and via coagulation.

According to this principle, the qualitative kinetic equation developed by Fitch and Tsai is:

$$
\left(\frac{d N}{d t}\right)=b R_{i w}-R_{c}-R_{f}
$$

where $t$ is the reaction time, $N$ the number of particles, $b$ a parameter that takes into account the aggregation of oligomeric radicals, $R_{i w}$ the effective rate of initiation or free-radical generation in the aqueous phase, $R_{c}$ the rate of capture of free-radicals, and $R_{f}$ the rate of coagulation of the particles.

Feeney, Napper and Gilbert proposed a different particle nucleation theory, which resembles homogeneous nucleation [50]. They showed that particle size distributions during particle formation (Interval I) were positively skewed, confirming the role of coagulation. They called this phenomenon as "coagulative nucleation" mechanism. They also have provided evidence that there can be coagulation even when the initial emulsifier concentration is above the CMC. It is possible that so many particles called "precursor" could be formed probably by homogeneous nucleation. Their size could be too small, and hence their surface area so much during growth, that they 'run out of' sufficient stabilizer providing their colloidal stability. This would result in coagulation in which the volume growth of the precursor particles by coagulation is much faster than that by propogation reactions. When these particles are sufficiently large to absorb appreciable amounts of monomer, "mature" primary latex particles occur. Monomer within the mature primary particles polymerizes more quickly than it those within the precursor particles. Because, the higher surface area of the precursor particles reduce the equilibrium swelling of the polymer by monomer, and hence the monomer concentration decreases. The smaller particles also can cause to exit of the free-radicals from the particles more easily. Consequently, the polymerization rate of the precursor particles decreases with increasing time due to these 
two effects. In the other hand, the positively skewed implies that the rate of particle nucleation increases with increasing time, and Feeney, Napper and Gilbert have explained that this skewed is a result of the coagulative nucleation.

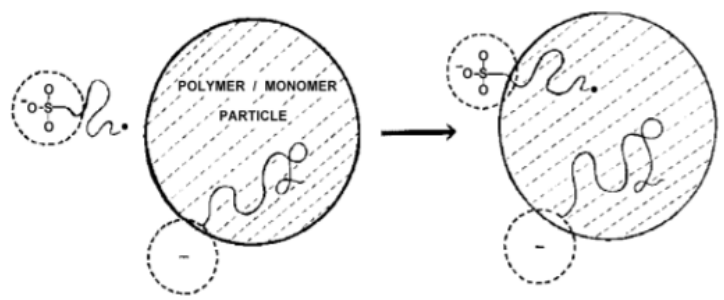

Figure 2. Capture of radicals by a particle in homogeneous nucleation [14]

\subsection{Other types of emulsion polymerization}

Oil-in-water emulsion polymerization systems are typically classified as possessing the characteristics of one of three types of emulsions: macro-emulsions, mini-emulsions or microemulsions. These emulsions are the initial systems for emulsion polymerization. There are quite differences between these systems in some aspects such as the size of the droplets (i.e. the discontinuous or dispersed phase), the interfacial area of the droplets, the particle nucleation mechanism and the stability of the emulsion.

Macro-emulsion polymerizations: The conventional emulsion polymerization is referred as macro-emulsion polymerization. In this chapter, all explanations included so far relate to macro-emulsion polymerization. It is initially composed of a monomer emulsion of relatively large $(1-100 \mu \mathrm{m})$ monomer droplets and significant free or micellar emulsifier. This emulsion is thermodynamically unstable, but kinetically stable. Phase separation is rapid unless the system is well agitated. In macro-emulsion polymerizations, the nucleation takes place outside the monomer droplets which generally do not contribute to the particle nucleation due to their very small droplet surface area. The monomer droplets act as only monomer reservoirs which supply the monomers to the polymerization loci through the aqueous phase.

Micro-emulsion polymerization: In micro-emulsion polymerization, the initial system is microemulsion which consist of monomer droplets (varying from 10 to $100 \mathrm{~nm}$ ) dispersed in water with the aid of a classical emulsifier (e.g. sodium dodecyl sulfate, SLS) and a "cosurfactant" such a low molar mass alcohol (pentanol or hexanol). Micro-emulsions are thermodynamically stable and optically one-phase solution. There is an excessive amount of emulsifier in these emulsions. Therefore, they are concentrated systems of micelles and the micelles exist throughout the reaction. One of the most interesting aspects of these micelles is their ability to accommodate monomer molecules. Furthermore, their high total surface area relative to nucleated particles implies the monomer-swollen micelles preferentially capture primary radicals generated in the continuous aqueous phase. Then the probability 
of capturing radicals by the micelles remains essentially one during the entire process and new particles thus are formed continuously. A growth in micellar size is always observed during the reaction due to the internal dynamics of micro-emulsions. This takes the form of either coagulation active and inactive micelles or the diffusion of monomer from the unreacted micelles to the nucleated particles. Reaction rates can be very fast. Finally, the small latex particles less than $50 \mathrm{~nm}$ are obtained from micro-emulsion polymerization. They on the average contain only one polymer molecule with average molecular weight exceeding one million [14-15,51].

Mini-emulsion polymerization: Mini-emulsions are produced by dispersing monomer in water by means of vigorous mechanical agitation or homogenization using a mixed emulsifier system including a classical emulsifier and a water-insoluble "co-surfactant" such as a long chain fatty alcohol or alkane (e.g. cetyl alcohol or hexadecane). The stability of miniemulsions can continue for as little as days and as long as months. The polymerization of these emulsions can begin with submicrometre monomer droplets (from 50 to $500 \mathrm{~nm}$ ). The long chain co-surfactants penetrate less the oil-water interface than the small monomer molecules, thus the emulsifier molecules move closer together, decreasing the interfacial area. Hence, the monomer droplets formed smaller size can become predominant particle nucleation loci provided that the total monomer droplet surface area becomes large enough to compete effectively with the continuous aqueous phase, in which particle nuclei are generated, for capturing waterborne free-radicals (monomer droplet nucleation). For propagation, the monomer is provided from within the polymerizing particles. Not all monomer droplets become polymer particles. Monomer droplets can be disappeared by another mechanism different from nucleation such as monomer diffusion to growing particles or by collision with polymer particles. No free, monomer-swollen micelles are present in this system since excess emulsifier has been adsorbed onto the large dropletwater interfacial area. The final polymer particles have almost the same size as the initial monomer droplets. Their size is often larger and their particle size distribution is broader than those obtained by conventional means of homogeneous or micellar nucleation $[15,52-$ 54].

In contrast to these oil-in-water emulsions, it is possible that the emulsion polymerization can also be carried out with inverse emulsions. Inverse (water-in-oil) emulsion polymerization in which an aqueous solution of a water miscible hydrophilic monomer such as acrylamide, acrylic acid, or methacrylic acid is dispersed in a continuous hydrophobic oil phase with the aid of a water-in-oil emulsifier such as sorbitan mono-oleate or -stearate. The emulsifier is ordinarily above the CMC. Polymerization can be initiated with either oil-soluble or watersoluble initiators. If an oil-soluble initiator is used, the system is an almost exact 'mirrorimage' of a conventional emulsion polymerization system. The final latex is a colloidal dispersion of submicroscopic, water-swollen particles in oil. This type of emulsion polymerization enables the preparation of high molecular weights water-soluble polymers at rapid reaction rates. It is also possible that the water-swollen polymer particles produced by this emulsion polymerization transfer to aqueous phase rapidly by inversion of the latex. 
As well as "inverse emulsion polymerization", there is also "inverse micro-emulsion polymerization" $[15,51,55]$.

\subsection{Types of emulsion polymerization process}

Three types of process are commonly used in carrying out the emulsion polymerization: batch, semi-continuous, and continuous. This classification is made according to the way in which the Interval II and Interval III reactions are effected [29].

Batch process: The batch-type process is the simplest method for effecting emulsion polymerization. All ingredients are placed in a reactor at the beginning of the reaction. The system is agitated, and heated to reaction temperature. Polymerization begins as soon as the initiator is added. Then, the reaction system is kept there by heating or cooling, as needed, and by agitating until the samples removed indicate the desired conversion of monomer to polymer. The only significant changes which can be made in such cases are to the reaction temperature, reactor design and the type and speed of agitation. Emulsion polymerization behavior in batch process can be divided into three intervals, as clearly explained in section 2.2: Interval I, free-radicals generated in the aqueous phase enter micelles and form new polymer particles. In Interval II, particles grow by continuously feeding of monomer from monomer droplets. In Interval III, polymerization continues in the monomer-swollen particles. During Interval III of a batch process, monomer concentrations in the polymer particles and in the aqueous phase decrease with time.

It is commonly used in the laboratory to study reaction mechanism and kinetics, but most commercial latexes are not manufactured by this process because of their undesirable properties. This process has the important disadvantages that limited control is exerted over either monomer/polymer ratio in the reaction loci, or over heat transfer in the reaction, or over copolymer composition. Nevertheless, batch process has an important role, particularly in more fundamental studies.

Semi-continuous (or semi-batch) process: This process is very versatile and is widely used, both industrially and in academic laboratories. Semi-continuous emulsion polymerization offers great degree of operational flexibility than batch or continuous processes. It allows one great control over the course of the polymerization, the rate of heat generation, and the properties and the morphology of the polymer latex particles. It also makes it possible to achieve relatively high polymer quality such as homogeneous chemical composition and particle size distribution.

The semi-continuous emulsion polymerization processes is characterized by continued addition of reaction ingredients such as monomer, emulsifier, initiator, or water to the reaction system throughout the polymerization. In this emulsion polymerization process, two major types of feeds are used for the introduction of ingredients to the reactor; neat monomer feed (M) or monomer emulsion feed (ME). In $\mathrm{M}$ feed method, the feed contains only monomer and all the other ingredients are initially in the reactor. Otherwise, the major components of the ME feed are a monomer, a part from the emulsifier, and water. But it 
contains other ingredients. The main difference between the two types is the emulsifier concentration throughout the polymerization. The initiator can initially be charged or/and continuously fed during polymerization. By the continuous addition of the emulsifier, monomer, and initiator to the reaction mixture, the mechanisms (especially particle formation) and kinetics of the semi-continuous emulsion polymerization process become more complicated in comparison with the batch counterpart. Both types of feed can be added to the reactor at any desired time or feeding rate during the feed addition stage. Generally, two types of feed addition strategy have been applied: monomer-flooded and monomer-starved. In the monomer-flooded type, the rate of monomer addition is higher than the maximum polymerization rate attainable by the system. The monomer accumulates in the system as monomer droplets and the polymer particles are saturated with the monomer, as in Interval II of a batch process. In the monomer-starved type, the rate of addition is lower than the rate of polymerization and the polymerization reaction occurs in Interval III where particles are not swollen to their maximum size, leading to the production of small sized, high solid content latexes [56-66].

A semi-continuous process generally contains three successive operations: seeding batch stage (or preliminary batch), feed addition semi-continuous stage and finishing batch stage. Generally, a semi-continuous process starts with a seeding batch stage which is the most critical stage of a semi-continuous process. It controls the particle formation in the whole course of the reaction. Therefore, the distributions of ingredients between initial reactor charge and feed have a great effect on the particle formation. The time interval between initiation and the start of feeding, which is called the "pre-period" or "seeding time", will determine the duration of seeding batch. Further growth of polymer particles is achieved by absorption of the monomer from the feed. After the pre-period time, particle nucleation may be complete but, in some conditions, nucleation can continue during the feeding period. If no pre-period is allowed, the seeding proceeds during the feed addition stage. The feeding stage is generally known as the "growth stage" and is the only stage within the three stages defined above which is carried out semi-continuous wise. The finishing batch is carried out to reduce the amount of unreacted monomer remaining in the reaction mixture to a minimum [61,63-64].

Consequently, semi-continuous emulsion polymerization is an important process, which overcomes the disadvantages of the batch and continuous processes, for the manufacture of a variety of latex products because of its operational flexibility and, providing control on the polymerization and the properties of polymer and latex.

Continuous process: In this process, the reaction system is continuously fed to, and removed from, a suitable reactor at rates such that the total volume of system undergoing reaction at any instant is constant. There are two basic type reactors for effecting continuous emulsion polymerization: the continuous stirred-tank reactor (CSTR) and tubular reactor. In tubular system, the composition is constant with time at any given position in the reactor. They are generally unsatisfactory for industrial production because of the very long tube lengths required, the poor degree of mixing and the difficulties of cleaning. They also require plug- 
flow in which the reacting mixture passes through the reactor without any forward or backward mixing. For the production of large amounts of the same product, the use of a CSTR may be preferable. In CSTR system, the reaction system is fed continuously to tank reactor, and from this reactor it is removed continuously at the same rate, the mixture in the tank being agitated to such an extent that it remains effectively homogeneous at all stage of the process. These reactors are characterized by isothermal, spatially uniform operation. There may be only one CSTR, or multiple CSTRs in a chain, the product from one being the feed for the next in the chain. The greater the numbers of CSTRs in a chain, the closer the properties approach those from a batch reaction. In such a system, residence time, which is defined as a finite time for remaining of the reaction system in the reactor, is important matter. Because, the performance of continuous flow reactor for emulsion polymerization in terms of conversion, particle concentration and particle size distribution strongly depends on the residence time distribution. Generally, conversion and particle number are lower and the particle size distribution is broader as compared to batch process. In particular, the particle nucleation stage is sensitive to residence time distribution $[14,29,67]$. Continuous emulsion polymerization process is useful for the production of commercial latexes. This process enables economical production of large volume, formation a highly uniform and well regulated product, and fewer problems with wall polymer buildup and coagulation. But, it allows less operational flexibility and less control on the product characteristics such as specific particle size distribution or particle morphologies [15].

Besides of this classification including the above three processes, another classification is also made according to the way in which the reaction loci are formed. By this way, two types of reaction system are defined: "ab initio emulsion polymerization" and "seeded emulsion polymerization" [29].

ab initio emulsion polymerization: In this type reactions, the particle nucleation (the generation of reaction loci) proceed in a significant period (during the early stage) of the reaction by mechanisms described as in section 2.2. No reaction loci are initially present.

Seeded (multi-stage) emulsion polymerization: In this reaction type, reaction loci are present in the initial system. The loci are formed by a separate reaction called as first stage of the emulsion polymerization. Thus, the particle nucleation stage of the reaction is eliminated by use of a pre-formed latex. Then, the pre-formed latex is introduced to the reaction mixture at the beginning. There must be enough seed particles to avoid new particles being subsequently nucleated. If the particle number is sufficiently high (typically, $\geq 10^{16}$ particles per liter is satisfactory), then the seed particles efficiently capture free-radical species from the aqueous phase and all primary particles that form by homogeneous nucleation (second stage of the emulsion polymerization). It is also possible that coagulation of tiny primary particles onto seed particles (heterocoagulation strongly affected by the surface charge on the seed particles) in the absence of emulsifier. When emulsifier is in the formulation, the amount of emulsifier must be just enough to maintain the colloidal stability of the seed latex particles as they grow through polymerization and/or coagulation with primary particles, but not so high as to generate new particles. In the second stage of the emulsion 
polymerization, monomer can be added to reaction system including seed particles by three different methods: dynamic swelling, batch and semi-continuous. By dynamic swelling method, the second stage is carried out after the seed particles are swollen with the second monomer. In batch method where seed latex has a second monomer added in the second stage of the emulsion polymerization. For semi-continuous method, the second monomer is continuously added in monomer-starved conditions to the reaction system including the seed latex during the second stage. In addition, one or more types of monomer can be used in both stages of the seeded emulsion polymerization. For example, in ABS (acrylonitrile/butadiene/styrene) polymer, polybutadiene (PB) seed latex is polymerized with a mixture of styrene and acrylonitrile monomers added in the second stage of the emulsion polymerization. As a result, it is possible to produce polymer particles with a wide variety of morphologies such as 'dumb-bell' shaped, 'ice-cream cone' shaped, 'raspberry' shaped, or core-shell due to the multi-stage emulsion polymerization process enables changing the experimental conditions in a wide range. Furthermore, this process provides many advantages in the production of latex particles being uniform and having excellent monodispersity in size. It also has high production yields. Such features make these latexes more practical in final uses for a wide variety of application areas [14,29.68-69].

\section{Emulsion polymerization of vinyl acetate}

The production of poly(vinyl acetate), PVAc latexes using poly(vinyl alcohol) as an emulsifier began in Germany during the mid-1930 [6]. Vinyl acetate, VAc emulsion polymerization recipes in use in Germany before and during World War II were originally disclosed in the BIOS (British Intelligence Objectives Subcommision) and the US FIAT (Field Intelligence Agency Technical) reports [7-8]. On the basis of these report information, manufacture of PVAc latex paints was begun in England in 1948. Afterwards, the production of PVAc latexes has continued to the present day, growing steadily over the years. During this period, too many studies have been done to explain the mechanism and kinetics of emulsion polymerization of VAc, to develop its polymerization conditions, and to improve the properties of PVAc latexes and their films. These subjects are still very important in both industrially and scientifically. Furthermore, VAc copolymers have been developed by using many kinds of comonomers such as ethylene, acrylates, maleates, vinyl chloride and versatic acid esters.

The industrial importance of VAc latexes necessitates the understanding of the mechanism and kinetics of VAc emulsion homopolymerization and copolymerizations with other comonomers by scientific communities as well as industrial communities. VAc is polymerized exclusively via free-radical polymerization. The emulsion homopolymerization mechanism of VAc is different from that of other vinyl monomers like styrene and butadiene. Although Smith-Ewart theory and related theories successfully explain the emulsion polymerization of nearly water-insoluble monomers, they are not fit the emulsion polymerization of VAc [4,70-71]. The most characteristic feature of VAc is its polarity and relatively high solubility in water in comparison with other hydrophobic monomers such as styrene. For example, the water-solubility value of VAc is $2.5 \%$ by weight at $20{ }^{\circ} \mathrm{C}$, while this 
value for styrene is $3.6 \times 10^{-2} \%$ [72]. Therefore, the initiation occurs in the aqueous phase and is explained by the "homogeneous nucleation" (as described in section 2.2). Another characteristic feature of VAc that affects the polymerization mechanism is its low reactivity and the correspondingly high reactivity of PVAc radicals in comparison with other vinyl monomers. This establishes the participation of the majority of components in the system in chain transfer during the polymerization of VAc. This has a substantial influence on the rate of polymerization, the molecular structure of the polymers, their branching, the tendency toward graft copolymerization, and also the tendency toward formation of significant amounts of gel fraction. In particular, the presence of a poly(vinyl alcohol), $\mathrm{PVOH}$ protective colloid in VAc emulsion polymerizations greatly affects branching and reaction mechanism. This agent is used as the principal surface-active substances in the system. More conventional emulsifiers may also be added to the system, but their role seems to be secondary that of this protective colloid. The chain transfer of PVAc to polymer, monomer and solvent (methanol) during emulsion polymerization in the absence of the $\mathrm{PVOH}$ is also a very important subject. As a result of these significant branching reactions of PVAc, there are considerable research results in literature on this subject [27,30,73-78].

Indeed, VAc has different features in comparison with other monomers in other respects than its water-solubility and the strong tendency of its radicals to the chain transfers. It has a high equilibrium monomer-polymer swelling ratio (values as great as $7: 1$ ). The heat of polymerization of VAc monomer is $21 \pm 0.5 \mathrm{kcal} / \mathrm{mole}$ [10]. Removing of the polymerization heat is of great importance in providing the control of the polymerization reaction. If not, a runaway exothermic reaction causes to uncontrollable boiling and consequent foaming or destabilization.

All these specific features of VAc monomer require a controlled emulsion polymerization process to be useful this monomer in particular industrial practice. The most commonly used process in the industrial practice of VAc emulsion polymerization is the delayed addition method in semi-continuous process. In this method, $5-15 \%$ of the VAc monomer is added into the reactor with some of the ingredients such as water, emulsifier and initiator at start. After the particle-generating period is completed, the remaining ingredients are incrementally during the polymerization. In some cases there is also gradual addition of remaining neat monomer and initiator when all other water phase ingredients are in the initial reactor charge. Additionally, many variations can be made in this process (see also section 2.4, semi-continuous process). The delayed addition process avoids the coalescence of the monomer-swollen latex particles, thus attaining greater colloidal stability. Emulsion prepared in this manner also show smaller particle size than emulsions prepared by the batch process. In the other hand, the semi-continuous process produces a broader molar mass distribution than the batch process and a high molar mass fraction which is attributed to chain transfer reactions due to monomer-starved conditions [15].

In the emulsion polymerization of VAc, the most commonly used initiators are the watersoluble, thermally decomposed, free-radical producing persulfates (peroxodisulfates) such as potassium-, sodium-, and ammonium-persulfate. Non-ionic and anionic emulsifiers (generally, mixtures of them) are the most widely preferred types because of improved 
compatibility with negatively charged PVAc particles as a result of persulfate initiator fragments. The use of protective colloids such as PVOH and hydroxyethyl cellulose (HEC) is common in the industrial emulsion polymerization of VAc. These water-soluble polymers can be used in the presence of emulsifier or in the emulsifier-free polymerization for the production of PVAc latexes and stable latexes can be made with only these protective colloids. The grafting reactions also take place between these protective colloids and VAc radicals, which influence the final product properties such as molar mass, viscosity and particle morphology. The VAc emulsion system is sensitive to changes of $\mathrm{pH}$ and the optimum $\mathrm{pH}$ range $(\mathrm{pH}=4.5-5.5)$ can be generally obtained by using sodium bicarbonate buffer system.

As a result of the emulsion polymerization of VAc monomer, an amorphous, non-crystalline and thermoplastic polymer is obtained. Poly(vinyl acetate) is soluble in alcohols, ketones, aromatic hydrocarbons and ethers. It can be also solubilized in emulsifier solutions. It absorbs 3 to $6 \mathrm{wt} \%$ water between 20 to $70{ }^{\circ} \mathrm{C}$ within $24 \mathrm{hrs}$. Moreover, in the presence of water, it can hydrolyze to form vinyl alcohol units and acetic acid, or the acetate of the basic cation. The minimum film forming temperature (MFFT), the glass transition temperature $\left(\mathrm{T}_{\mathrm{g}}\right)$ and the mechanical properties of the PVAc depend on the molecular weight. For medium molecular weight, its $\mathrm{T}_{\mathrm{g}}$ is approximately $30{ }^{\circ} \mathrm{C}$ and its MFFT is approximately 20 ${ }^{\circ} \mathrm{C}$. Its Young modulus is $600 \mathrm{~N} / \mathrm{mm}^{2}$ at $25{ }^{\circ} \mathrm{C}$ with $50 \%$ relative humidity. The tensile strength and the elongation at break of PVAc are between $29.4-49.0 \mathrm{~N} / \mathrm{mm}^{2}$ and $10-20 \%$ at $20{ }^{\circ} \mathrm{C}$, respectively [30]. These properties depend on not only the molecular weight of the polymer, but also the emulsion polymerization type, the ingredients of the polymerization and the particle morphology of the polymer. The thermal degradation of PVAc occurs at 150-220 ${ }^{\circ} \mathrm{C}$. PVAc is brittle on cooling below room temperature, i.e., at $10-15{ }^{\circ} \mathrm{C}$ [30].

Nevertheless, some of these properties of the PVAc make the VAc homopolymer latexes and its films unsuitable for many applications. For example, its films have low resistance against water, alkaline, and hydrolysis. They show poor mechanical properties. $\mathrm{Tg}$ and MFFT values of this homopolymer also constitute the major problems in its applications because the MFFT is too high for this polymer to perform as an effective binder for pigments and fillers at normal ambient temperatures. While the $\mathrm{T}_{\mathrm{g}}$ is too low for the polymer to be useful as a rigid plastic at normal ambient temperatures, the same value is too high for application as a binder and an adhesive at the same temperatures. Due to these properties of the VAc homopolymer, VAc is copolymerized with other monomers such as ethylene, n-ethyl acrylate, n-butyl acrylate, 2-ethylhexyl acrylate, methyl methacrylate, vinyl chloride, vinyl propionate, vinyl versatate, maleates (dibutyl malate), fumarates, and acrylonitrile to improve the poor properties of this polymer. Terpolymers of VAc are also widely produced. The selection of comonomers to be used to produce VAc copolymer latexes for any given application depends principally upon the functional suitability of the comonomer and its coast. As well as the VAc homopolymer latex, The VAc based copolymer/terolymer latexes are widely used for exterior and interior architectural coatings, adhesives, textile and paper industry, and numerous other applications. 


\section{Effects of polymerization variables on the properties of vinyl acetate based emulsion polymers}

VAc monomer is a polar and reactive, and has the characteristic features. The significant differences between VAc and the comonomers lead to difficulties during copolymerization when the VAc is copolymerized with less polar and more reactive monomers. The emulsion copolymerization of VAc with the comonomers requires the special treatments. Other properties such as the copolymer structure, the particle morphology, and the colloidal, physical and film properties of the copolymer latex are also affected from this situation. In order to prevent potential problems and produce copolymer emulsion polymers in homogeneous copolymer structure and desired properties, the various processes and different ingredient systems are applied for VAc copolymerization systems. The major copolymerization systems of VAc and, the effects of copolymerization variables on the course of polymerization and the properties of emulsion copolymers are given in detail below.

One of the most important industrial latexes is the vinyl acetate/n-butyl acrylate (VAc/BuA) copolymer latex. This copolymer latex is utilized extensively in interior and exterior paints and is superior to either homopolymer alone. The main features of these monomers are: reactivity ratios $\left(\mathrm{rVAc}_{\mathrm{C}}=0.05\right.$ and $\left.\mathrm{rBuA}=5.5\right)$, water solubilities $(25 \mathrm{~g} / \mathrm{L}$ for $\mathrm{VAc}$ and $1-1.5 \mathrm{~g} / \mathrm{L}$ for $\mathrm{BuA}$, at $\left.20^{\circ} \mathrm{C}\right)$, and glass transition temperatures $\left(\mathrm{T}_{\mathrm{g}}(\mathrm{PVAc})=32{ }^{\circ} \mathrm{C}\right.$ and $\left.\mathrm{T}_{\mathrm{g}}(\mathrm{PBuA})=-54{ }^{\circ} \mathrm{C}\right)$. The presence of $\mathrm{BuA}$ in VAc emulsion copolymerizations results in internally plasticized copolymers with MFFTs in the ambient temperature range. BuA also imparts softness and tackiness, and thus the durability of VAc copolymer increases. Although polyacrylates and polymethacrylates are less susceptible to hydrolysis than the PVAc, VAc/BuA emulsion copolymers show sensibility to hydrolysis. In industry, $15-25 \%$ by weight of $\mathrm{BuA}$ is preferred.

The emulsion polymerization process types, especially batch and semi-continuous processes, are very effective on the $\mathrm{VAc} / \mathrm{BuA}$ copolymerization and the obtained copolymers. In batch and semi-continuous emulsion processes of VAc/BuA comonomer mixtures having various compositions, homogeneous copolymer compositions are obtained only by semi-continuous process. In contrast, batch process produces the VAc/BuA latexes in heterogeneous copolymer composition. Due to the significantly differences in water solubility and reactivity ratio of this monomer couple, the semi-continuous process provides better control over compositional heterogeneity than batch process for this monomer couple [27,79-82]. The copolymer latexes produced by batch process have a larger average particle size (PS) and narrower particle size distribution (PSD) than the latexes produced by semicotinuous process. By increasing of $\mathrm{BuA}$ content in comonomer mixture the average particle size of semi-continuous latexes decreases, whereas it is independent of comonomer composition for batch-latexes [27,80,82-86]. In addition, the particle structures of batchlatexes have a larger BuA-rich core surrounded by a PVAc-rich shell, indicating heterogeneous structure, than the semi-continues latex particles [80]. Also, the ratio of each monomer on particle surface depending on the process type and copolymer composition 
effects hydrolysis and electrolyte resistance of the latexes $[27,82]$. The broader molecular weight distribution (MWD) with bimodal character is observed for semi-continuous copolymers. The MWD of batch copolymers are broad, but they are narrower and in unimodal character in comparison to those of semi-continuous copolymers. This results for both processes indicates the excessive branching reactions $[27,82-85,87]$. When the film properties of $\mathrm{VAc} / \mathrm{BuA}$ copolymer latexes of various copolymer composition are examined, it is seen that the semi-continuous process provide better properties to copolymer films such as filming ability and film homogeneity (examined according to the $\mathrm{T}_{\mathrm{g}}$ and surface analyzes) than the batch process $[27,88]$. The homogeneity influences hardness and adhesive properties of latexes as well as copolymer composition, and hardness decreases with increasing homogeneity [79]. The thermodynamic work of adhesion decreases with increasing $\mathrm{BuA}$ content for semi-continuous copolymer films [86]. In contrast, tensile properties of the batch copolymer films show a higher ultimate tensile strength, higher Young's modulus, and lower percent elongation to break compared to semi-continuous latex films $[27,88]$. In addition, by the increase of BuA content in the copolymer, the film abilities increase and $\mathrm{T}_{\mathrm{g}}$ values decrease for copolymers produced by both process $[27,85$ 86,88].

The semi-continuous copolymerization of $\mathrm{VAc} / \mathrm{BuA}$ monomer system can be carried out by applying different addition policy of copolymerization ingredients. In the copolymerization of $\mathrm{VAc} / \mathrm{BuA}$ system having a certain monomer ratio, the monomer addition type directly affects the course of copolymerization. For seeded-semi-continuous copolymerizations in which a certain part of monomer present in the initial reactor charge as a remaining part in the feeding, the polymerization rate approaches a constant value depending on the monomer addition rate when the monomer-starved feed addition strategy is applied (for a neat monomer feed method). It increases with increasing monomer addition rate, and approaches the rate observed for batch polymerization when the feed rates exceed the maximum values for monomer -starved conditions. In the other hand, the polymerization rate is at maximum and independent upon the monomer feed rate when monomer-flooded condition is applied $[87,89]$. Furthermore, for the semi-continuous process of $\mathrm{VAc} / \mathrm{BuA}$, micro-phase separation in particle structure is revealed, and the feeding rate of comonomers influences the change in this particle morphology of copolymers. The faster feeding rate causes to greater separation while a multi-core-shell structure is formed with the slowest feeding [90]. The initiator addition policy also affects the polymerization rate, the instantaneous monomer conversion, the average PS and PSD, and the polymerization stability of the $\mathrm{VAc} / \mathrm{BuA}$ semi-continuous emulsion systems. Increasing the amount of ammonium persulfate initiator in the initial reactor charge leads to increase the rate of polymerization and the conversion. But it is observed that this amount is increased above a certain value, destabilization occurs and the average PS increase [91-92].

The stabilizing system significantly affects many colloidal and film properties of the $\mathrm{VAc} / \mathrm{BuA}$ emulsion copolymers. Berber and co-workers studied the semi-continuous emulsion copolymerization of this comonomer system in the presence of conventional nonionic emulsifiers and different protective colloids which were water-soluble polymer 
(PVOH) and polymerizable oligomeric N-methylol acrylamide (o-NMA). The VAc/BuA copolymer latexes obtained by o-NMA at different copolymer compositions were found to have lower viscosity, finer particle size, better latex stability and lower MWD and their films showed the higher $\mathrm{T}_{\mathrm{g}}$, better film forming behavior and better water resistance, compared to those synthesized by PVOH. Figure 3 shows the effect of the BuA content and the stabilizing system on the $\mathrm{Tg}_{\mathrm{g}}$ of the $\mathrm{VAc} / \mathrm{BuA}$ latex films [85]. They also compared the effects of two different initiator systems which consist of ammonium persulfate and potassium persulafte, on the properties of $\mathrm{VAc} / \mathrm{BuA}$ copolymers synthesized in presence of o-NMA. It was seen that the particle size of copolymers varied by the increasing BuA content in the copolymer regardless of the type of initiator. Otherwise, for the all copolymer compositions, molecular weights (MWs) of the copolymers synthesized in the presence of potassium persulfate were found to be higher and the latex viscosities of them were lower, than those of $\mathrm{VAc} / \mathrm{BuA}$ copolymers synthesized in the presence of ammonium persulfate [83].

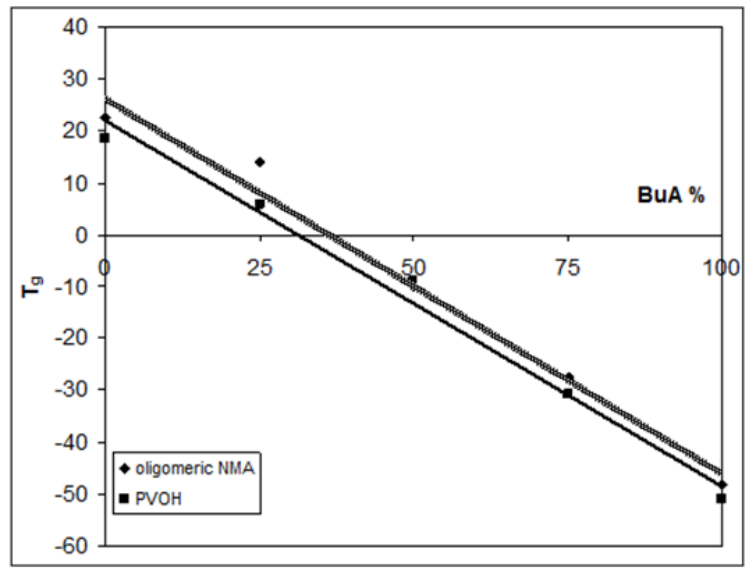

Figure 3. Changes in $\mathrm{T}_{\mathrm{g}}$ with copolymer composition for VAc/BuA copolymer latexes obtained by o$\mathrm{NMA}$ and $\mathrm{PVOH}[85]$

The seeded emulsion polymerization process can be applied for VAc/BuA comonomer system. Seeded reactions allow for the production of mono-dispersee latexes. Key factors in producing narrow PSD latexes are concentration of seed latex and ionic strength. The increasing of seed latex concentration ( $55 \%$ by weight) causes to the largest mono-dispersee particles [93].

The emulsion copolymerization of $\mathrm{VAc} / \mathrm{BuA}$ monomer system can be performed by other emulsion polymerization methods, mini-emulsion and micro-emulsion polymerizations. When the mini-emulsion copolymerization carries out with the 50/50 molar ratio of $\mathrm{VAc} / \mathrm{BuA}$ in the presence of sodium hexadecyl sulfate emulsifier, hexadecane co-surfactant and ammonium persulfate initiator, the results of this polymerization conducted in a batch process are different from that of conventional batch polymerization of this monomer couple [94]. For the mini-emulsion polymerization the polymerization rate is slowed done, 
the final particle size is larger and the coagulation during the polymerization occurs, compared to the conventional batch process. There is also less mixing between the BuA-rich core and VAc-rich shell. The presence of co-surfactant makes significant effects to both of course of the copolymerization and the resulting latex and films [94].

The emulsion copolymerizations of vinyl acetate with maleic acid diesters such as dibutyl maleate (DBM) and dioctyl maleate (DOM) are also possible. These diesters are easily copolymerized but can not homopolymerize. The main features of these monomer couples are: reactivity ratios ( $\mathrm{rVAc}_{\mathrm{C}}=0.171$ and $\mathrm{rDBM}_{\mathrm{D}}=0.046$; $\mathrm{rVAc}_{\mathrm{V}}=0.195$ and $\mathrm{rDOM}=0.945$ ) and water solubilities (25 g/L for VAc, $0.35 \mathrm{~g} / \mathrm{L}$ for DBM and almost zero for DOM, at $20{ }^{\circ} \mathrm{C}$ ) [95-96]. Because of the significantly different monomer properties between VAc and these maleic acid diesters, copolymer latexes having a wide range of properties can be obtained by varying the comonomer composition, thus influencing the glass transition temperature and minimum film forming temperature of the latexes. The use of these comonomers provides internal plastification to VAc polymers and they reduce the Tg value of them. The hardness, flexibility, and alkali, water and ultra-violet light resistance of their films can be improved. Furthermore, these diesters gain more stability to the copolymer latex by being strongly associated to the latex particles. It is then expected that the final properties of the copolymers will be enhanced and will not be altered during time due for instance to the migration of the plasticizer. The copolymers of VAc/Maleic acid diester are used for paints and adhesives.

Although these copolymers are industrially very useful, there are no more scientific researches about them. The earliest studies in the literature about the VAc/Maleic acid diester copolymers belong to Donescu and co-workers [57,97]. They investigated the semicontinuous emulsion polymerization of VAc and DBM (VAc/DBM: 60/40 by volume). They used PVOH, 20 moles ethoxylated cetyl alcohol and potassium persulfate as protective colloid, emulsifier and initiator respectively. The seeded-semi-continuous process was carried out by applying monomer emulsion feed method. The effects of emulsifier distribution between initial reactor charge and continuously introduced monomer, and agitation speed on the monomer conversion and copolymer structure were also investigated. They observed decrease in the polymerization rate with an increase of agitation speed. On the other hand, the transfer reactions were higher for the smaller speed. When the influence of the emulsifier distribution on conversion was examined, it was seen that the conversion increased and then decreased with the increasing initial reactor charge concentration of emulsifier. This behavior has been explained that the chain transfer effect of emulsifier is more pronounced over a certain emulsifier concentration. The emulsifier and DBM act as chain transfer agent in this type emulsion copolymerization of VAc/DBM [57]. In addition, Donescu and Fusulan copolymerized VAc with DBM using a semi-continuous process for different copolymer compositions. They also noticed a decrease in particle size with increasing DBM monomer. The retarding effect of DBM on the VAc polymerization was also determined [98]. In another study, Donescu and co-workers copolymerized VAc with another type of maleic acid diesters, 2-ethylhexyl maleate which is synonym for DOM, by semi-continuous emulsion polymerization [97]. They used a different stabilizing system 
including hydroxylethyl cellulose (HEC) as protective colloid and sodium sulfosuccinate of 6 moles ethoxylated nonyl phenol as emulsifier compared to the VAc/DBM system. They also used n-butanol as chain transfer agent. The comonomer addition was applied in flooded conditions for a certain comonomer ratio, VAc/2-ethylhexyl maleate: 80/20 by volume). They investigated the effect of HEC on the particle number, conversion, and latex surface tension during the copolymerization. The oscillations occurred in these investigation parameters due to the flocculation and nucleation of new particles. The authors suggested that HEC splits its chain in the presence of the initiator, thus continuously stabilizing the new particles formed. In theVAc/2-ethylhexyl maleate copolymerization system, it was seen that the copolymerization rate and conversion decreased with the increasing agitation rate. The higher the agitation rate also affected the average PS of copolymers, and the smaller the PS found up to $600 \mathrm{rpm}$ agitation rate. In addition, the presence of n-butanol in that reaction system decreased the average particle diameter and cross-linked copolymer content.

$\mathrm{Wu}$ and Schork also studied the copolymerization of VAc/DOM for different compositions of monomer mixture. They compared the conventional (macro-) and the mini-emulsion polymerization by applying both of batch and semi-continuous process [95]. In their study, a certain difference in PSs and particle numbers between macro-emulsion and miniemulsion feed semi-continuous operation is seen. The PS is smaller and the particle number is higher. The size decreases with a decrease in feed rate for both macro- and mini-emulsion polymerization. The PSs in semi-continuous operations are smaller than in batch miniemulsion polymerizations when the feed rate of monomer emulsion is sufficiently low. For batch copolymerizations of VAc and DOM, the rate of macro-emulsion polymerization is faster than that of mini-emulsion polymerization while the particle number increases with increasing conversion throughout the reaction for both macro- and mini-emulsion processes. Due to the extremely water-insoluble DOM monomer, a significant deviation in the composition of the VAc/DOM copolymer is observed. The most homogeneous compositions are obtained by mini-emulsion copolymerizations and the coagulation resistance of this emulsion polymerization system is better than that of macro-emulsion process, as well. For both of macro- and mini-emulsion polymerizations, the increasing concentration of DOM in the monomer mixture results in a reduction of the total polymerization rate and reduction of the copolymer MW.

Berber investigated the effects of some polymerization variables such as process type, initiator addition type, emulsifier type and its distribution between the initial reactor charge and feed, and feeding time on the monomer conversion, the latex stability and the average particle size for semi-continuous emulsion copolymerizations of VAc with DOM (VAc/DOM: 60/40, by weight) [99]. The emulsion copolymerizations were carried out in the presence of potassium persulfate as initiator and o-NMA as polymerizable co-stabilizer. A mixture of monomers, such as including VAc and DOM, should be added to reaction medium by the monomer emulsion feed method because of the large water-solubility differences between the two monomers. Thus, the selected emulsifier system should constitute "pre-emulsion" for monomer emulsion feed of the monomer couple. For the mixture of VAc and DOM monomers, anionic and non-ionic emulsifiers such as sodium 
dodecylbenzene sulfonate (Maranil A 25), dioctyl sodium sulfosuccinate (Disponil SUS 87), sodium lauryl ether sulphate (SLES), 30 and 10 moles ethoxylated nonyl phenoles (NP 30 and NP 10), and their combinations were used. The non-ionic emulsifiers system consisting of equal amounts of NP 30 and NP 10 which can form stable pre-emulsion and can produce stable copolymer latex was selected as suitable emulsifier system for VAc/DOM emulsion copolymerization (Table 1). The change of emulsifier concentration in the initial reactor charge (from $0 \%$ to $33 \%$, by weight) affected the stability of polymerization and the average PS of copolymer latexes. The very high or the very low concentrations of emulsifier in the initial charge caused to polymerization instability and increase in average PS (Table 2).

\begin{tabular}{|l|c|c|}
\hline Emulsifiers & Stable Pre-emulsion & Stable Latex \\
\hline Maranil A 25 & - & - \\
\hline Disponil SUS 87 & - & - \\
\hline SLES & - & - \\
\hline NP 30 & - & - \\
\hline NP 10 & - & - \\
\hline$\% 70$ SLES + \% 30 NP 10 & $\checkmark$ & - \\
\hline$\% 30$ NP 30 + \% 70 NP 10 & $\checkmark$ & $\checkmark$ \\
\hline$\% 50$ NP 30 + \% 50 NP 10 & $\checkmark$ & - \\
\hline
\end{tabular}

Table 1. The effects of emulsifier type on the stability of pre-emulsion and resulting latex for VAc/DOM system

\begin{tabular}{|c|l|c|}
\hline $\begin{array}{c}\text { Emulsifier concentration in } \\
\text { initial reactor charge }(\%, w / w)\end{array}$ & Appearance of latex & Particle size $(\mathrm{nm})$ \\
\hline 33 & $\begin{array}{l}\text { Creaming and incrustation on the } \\
\text { latex surface }\end{array}$ & 284 \\
\hline 25 & $\begin{array}{l}\text { Partially incrustation on the latex } \\
\text { surface }\end{array}$ & 221 \\
\hline 0 & $\begin{array}{l}\text { Coagulation and incrustation on the } \\
\text { latex surface }\end{array}$ & 482 \\
\hline
\end{tabular}

Table 2. The effects of emulsifier concentration in initial reactor charge on the stability and the particle size of latex for VAc/DOM system

In addition, the presence of seeding stage in the semi-continuous process (by $10 \mathrm{wt} \%$ monomer), the increasing of the feeding time and better control of the initiator feed increased the monomer conversion, the average particle size, and the stabilities of the polymerization and latex of $\mathrm{VAc} / \mathrm{DOM}$ monomer system. The effect of these reaction variables on the conversion and the particle size of the VAC/DOM latex are given in Table 3 [99]. 


\begin{tabular}{|c|l|l|l|l|c|c|}
\hline $\begin{array}{l}\text { Monomer } \\
\text { content in initial } \\
\text { reactor charge } \\
(\%, \mathrm{w} / \mathrm{w})\end{array}$ & $\begin{array}{l}\text { Seeding } \\
\text { stage }\end{array}$ & $\begin{array}{l}\text { Feeding } \\
\text { stage }\end{array}$ & $\begin{array}{l}\text { Completion } \\
\text { stage }\end{array}$ & Initiator feed & $\begin{array}{l}\text { Conversion } \\
(\%)\end{array}$ & $\begin{array}{l}\text { Particle } \\
\text { size } \\
(\mathrm{nm})\end{array}$ \\
\hline- & - & $\begin{array}{l}70^{\circ} \mathrm{C}, \\
2.5 \mathrm{~h} .\end{array}$ & $\begin{array}{l}70^{\circ} \mathrm{C}, \\
30 \mathrm{~min} .\end{array}$ & $\begin{array}{l}\text { as } 5 \text { portion } \\
\text { during feeding } \\
\text { time }\end{array}$ & 82 & 145 \\
\hline 10 & - & $\begin{array}{l}70^{\circ} \mathrm{C}, \\
3 \mathrm{~h} .\end{array}$ & $\begin{array}{l}70^{\circ} \mathrm{C}, \\
1 \mathrm{~h} .\end{array}$ & $\begin{array}{l}\text { as drop wise } \\
\text { during feeding } \\
\text { time }\end{array}$ & 86 & 160 \\
\hline $\begin{array}{l}30 \mathrm{~min} . \\
\text { at } 65^{\circ} \mathrm{C} \\
+ \\
30 \mathrm{~min} . \\
\text { at } 70^{\circ} \mathrm{C}\end{array}$ & $\begin{array}{l}70^{\circ} \mathrm{C}, \\
5 \mathrm{~h} .\end{array}$ & $\begin{array}{l}80{ }^{\circ} \mathrm{C}, \\
1 \mathrm{~h} .\end{array}$ & $\begin{array}{l}\text { half of the total } \\
\text { amount at } \\
\text { beginning of } \\
\text { the reaction } \\
+ \\
\text { the remaining } \\
\text { amount as } \\
\text { drop wise } \\
\text { during feeding } \\
\text { time }\end{array}$ & 95 & 221 \\
\hline
\end{tabular}

Table 3. The effect of some polymerization variables on conversion and particle size of VAc/DOM latex

Vinyl versatate monomer (vinyl ester of versatic acid) is a commercial product of Shell Chemicals and called as VeoVA. It is a branched vinyl neodecanoate, and this branched vinyl ester (VeoVA 10) is copolymerized with VAc. The reactivity ratios of VAc and vinyl neodecanoate are respectively 0.99 and 0.92 . The water solubilities are $25 \mathrm{~g} / \mathrm{L}$ for VAc and $0.1 \mathrm{~g} / \mathrm{L}$ for vinyl neodecanoate at $20^{\circ} \mathrm{C}$. The glass transition temperatures are $32{ }^{\circ} \mathrm{C}$ for PVAc and $-3{ }^{\circ} \mathrm{C}$ for polyVeoVa. VeoVA can act as internal plasticizer in VAc emulsion copolymers. The most distinguishing feature of these branched vinyl esters is their resistance to hydrolysis, both as monomers and in polymers. Polymerization of branched vinyl esters with VAc results in polymers whose hydrolytic stability improves with increasing concentrations of branched vinyl ester. Higher molar mass vinyl branched esters offer excellent hydrophobic properties. These esters are strongly resistant to saponification, water absorption and UV degredation. The properties of VAc polymer such as water and alkali resistance and exterior durability improve with these esters. These all advantages make the VAc/branched vinyl ester copolymers more suitable for applications. They are used in architectural paints, interior and exterior applications, and general markets, Typically, about $15-30 \%$ VeoVa-10 is used to optimize the cost-performance properties of VAc polymers. Interior latexes tend to contain 15-20\% monomer. Exterior latexes usually contain $20-30 \%$ of the branched monomer [15,30]. The high solids emulsion copolymerization of VAc and VeoVA 10 can be carried out in a continuous industrial reactors, continuous loop reactor and continuous stirred tank reactor (CSTR). When the heat 
generation rate is high a thermal runaway occurred in the CSTR reactor, whereas the loop reactor is easily controlled [100].

For the emulsion copolymerizations of VAc, methyl methacrylate (MMA) comonomer is added to increase the $\mathrm{T}_{\mathrm{g}}$ of the VAc polymer. The homopolymer of the MMA has a $\mathrm{T}_{\mathrm{g}}$ of approximately $106^{\circ} \mathrm{C}$. The other features of these monomers are: reactivity ratios (rvAc $=0.03$ and $\left.\mathrm{rMMA}_{\mathrm{m}}=22.21\right)$ and water solubilities $\left(25 \mathrm{~g} / \mathrm{L}\right.$ for VAc and $16 \mathrm{~g} / \mathrm{L}$ for MMA, at $\left.20{ }^{\circ} \mathrm{C}\right)$ [15]. This comonomer also imparts hardness and no tackiness. VAc/MMA emulsion copolymers have unlimited uses. VAc can also be copolymerized with other acrylates such as methylacrylate (MA), 2-ethylhexyl acrylate (2-EHA) by emulsion polymerization. The main features of these monomers are: reactivity ratios ( $\mathrm{rvAc}_{\mathrm{c}}=0.04$ and $\mathrm{rMA}_{\mathrm{M}}=7.5 ; \mathrm{rvAc}_{\mathrm{c}}=0.029$ and rEHA=6.7), water solubilities ( $25 \mathrm{~g} / \mathrm{L}$ for VAc, $0.1 \mathrm{~g} / \mathrm{L}$ for 2-EHA and $52 \mathrm{~g} / \mathrm{L}$ for MA, at $20{ }^{\circ} \mathrm{C}$ ) and glass transition temperatures $\left(\mathrm{T}_{\mathrm{g}}(\mathrm{PVAc})=32{ }^{\circ} \mathrm{C}\right.$ and $\left.\mathrm{T}_{\mathrm{g}}(\mathrm{PMA})=22{ }^{\circ} \mathrm{C}\right)$ [30]. 2-EHA is a softer monomer and adds durability to the copolymer. The tack of the final copolymer films increases when this comonomer is used in high concentrations. The terpolymerizations of these comonomers are also possible with VAc and other acrylates [15,30].

Moreover, some water-soluble functional monomers can be used in emulsion copolymerizations or terpolymerizations. Acrylic acid, methacrylic acid, fumaric acid, crotonic acid, maleic acid, itoconic acid, N-methylol acrylamide and some polymerizable monomer containing amines, amides and acetoacetates are used alone and in combination with each other to improve the stability and adhesion properties of VAc emulsion polymers.

The presence of acid comonomers decreases the rate of reaction and icreases PS. Also, it leads to the splitting reactions of the potassium persulfate initiator [101]. Acid comonomer groups in the copolymer structuture act as effective thickeners and impart good blending properties with inorganic additives. Carboxylic groups located on the particle surface impart high $\mathrm{pH}$ and high stability The minor amount of acid comonomers is used to modify VAc/acrylates copolymer emulsions [102]. Acrylic acid (AA) and methacrylic acid (MAA)modified $\mathrm{VAc} / \mathrm{BuA}$ or $\mathrm{VAc} / 2$-EHA copolymer latexes are used in the pressure-sensitive adhesive market. The feeding of the acid comonomers in the monomer feed produces a greater viscosity response upon $\mathrm{pH}$ adjustment compared to a water solution feed of them [70]. Minor amounts of $\mathrm{N}$-methylol acrylamide are sometimes used impart cross-linking and heat-set properties to the VAc homopolymer and VAc/acrylate copolymers, especially in textile printing binder applications and adhesive applications for wood.

\section{Conclusion}

This chapter basically focused on the scientific and industrial importance of the emulsion polymerization and vinyl acetate based emulsion polymers from past to present. Firstly, the basic issues of conventional emulsion polymerization were given. Its ingredients, kinetics, and mechanisms were explained in detail. Other emulsion polymerization methods including micro-, mini- and inverse-emulsion polymerization were mentioned, followed by the description of main emulsion polymerization processes comprising batch, semi- 
continuous, continuous and seeded, and their application types. Secondly, the emulsion polymerization of vinyl acetate was given. The characteristic feature of vinyl acetate monomer, its emulsion polymerization conditions, and the main properties of its homopolymer latex were summarized. Finally, the emulsion copolymerizations of vinyl acetate with other monomers having specific features and industrially importance were discussed briefly. The effects of the copolymerization variables and the components on the course of emulsion polymerization and the properties of the resulting copolymers were explained, which was supported by the literature results.

\section{Author details}

Hale Berber Yamak

Department of Chemistry, Yildiz Technical University, Istanbul, Turkey

\section{References}

[1] Hoffman F and Delbrück K (1909) German Patent. 250,690 (to Farbenfabriken Bayer A.G).

[2] Hoffman F and Delbrück K (1912) German Patent. 254,672 (to Farbenfabriken Bayer A.G).

[3] Hoffman F and Delbrück K (1912) German Patent. 255,129 (to Farbenfabriken Bayer A.G).

[4] Dinsmore R.P (1929) U.S. Patent. 1,732,975 (to Goodyear Tire \& Rubber Co.).

[5] Luther M and Hück C (1932) U.S. Patent. 1,864,078 (to I.G Farbenindustrie A.G).

[6] Starck W and Freudenberg H (1940) U.S. Patent. 2,227,163 (to I.G Farbenindustrie A.G).

[7] B.I.O.S (British Intelligence Objectives Subcommision) (1947) Manufacture of Vinyl Acetate Polymers and Derivatives. Final Report 744. London: H.M.S.O.

[8] US FIAT (Field Intelligence Agency Technical) (1947) Polymerization of Vinyl Acetate. Final Report 1102. London: H.M.S.O.

[9] B.I.O.S (British Intelligence Objectives Subcommision) (1954) The German Plastic Industry During the Period 1939-1945. Surveys Report 34. London: H.M.S.O.

[10] Bovey F.A, Kolthoff I.M, Medalia, A.I, Meehan, E.J (1965) Emulsion Polymerization. High Polymer Series Vol. IX. New York: Interscience Publishers Inc.

[11] Blackley D.C (1975) Emulsion Polymerization, Theory and Practice. London: Applied Science Publishers.

[12] Eliseeva V.I, Ivanchev S.S, Kuchanov S.I, Lebedev A.V (1981). Emulsion Polymerization and Its Applications in Industry. New York: Plenum Publishing Corporation.

[13] Piirma I (1982) Emulsion Polymerization. New York:Academic Press.

[14] Fitch M.R (1997) Polymer Colloids: A Comprehensive Introduction. USA: Academic Press.

[15] Lovell P.A, El-Aasser M.S (1997) Emulsion Polymerization and Emulsion Polymers. England: Wiley. 
[16] Urban D, Takamura K (2002) Polymer Dispersions and Their Industrial Applications. Germany: Wiley-VCH Verlag GmbH \& Co.

[17] Whitby G.S, Davis C.C, Dunbrook R.F (1954) Synthetic Rubber. New York: Wiley.

[18] Hoelscher F (1969) Dispersionen Synthetischer Hochpolymeren, Part I. New York: Springer-Verlag.

[19] Ostromislensky I.I (1916) Condensation of Alcohols and Aldehydes in Presence of Dehydrating Agents. Mechanism of the Process J. Russ. Phys. Chem. Soc. 48:1071.

[20] Whitby G.S, Katz M (1933) Synthetic Rubber. Ind .Eng. Chem. 41: 1204-1211, 1338-1348.

[21] Berezan K, Dobromyslova A, Dogadkin B (1938) Synthetic Rubber From Alcohol. Bull. Acad. Sci. U.S.S.R. 7:409.

[22] Fikentscher H (1938) Emulsionspolymerisation und Technische. Angew. Chem. 51:433.

[23] Hohenstein W.P and Mark H (1946) polymerization of Olefins and Diolefins in Suspension and Emulsion. Part II. J. Polym. Sci. 1: 549-580.

[24] Talalay A, Magat B (1945) Synthetic Rubber from Alcohol: A Survey Based on the Russian Literaure. New York: Interscience.

[25] Williams H.L (1956) Polymerization in Emulsion In: Schildknecht C.H editor. Polymer Processes. New York: Interscience. pp. 111-171.

[26] Warson H (1972) Applications of Synthetic Resin Emulsions. London: Benn.

[27] El-Aasser M.S, Vanderhoff, J.W (1981) Emulsion Polymerization of Vinyl Acetate. London: Applied Science Publishers.

[28] Gilbert R.G (1995) Emulsion Polymerization-A mechanistic Approach. New York: Academic Press.

[29] Blackley D.C (1997) Polymer Latices Science and Technology. Volume 2. London: Chapman \& Hall.

[30] Erbil H.Y (2000) Vinyl Acetate Emulsion Polymerization and Copolymerization with Acrylic Monomers. Florida: CRC Pres.

[31] Herk A (2005) Chemistry and Technology of Emulsion Polymerization. Oxford: Blackwell Publishing.

[32] Winnik M.A (1997) The Formation and Properties of Latex Films. In: Lovell P.A, ElAasser M.S editors. Emulsion Polymerization and Emulsion Polymers. England: Wiley. pp. 468-470.

[33] Chern C.S (2006) Emulsion Polymerization Mechanisms and Kinetics. Prog. Polym. Sci. 31:443-486.

[34] Lijen C, Shi Y. L, Chorng S.C, Shuo C.W (1997) Critical Micelle Concentration of Mixed Surfactant SDS/NP(EO) 40 and Its Role in Emulsion Polymerization. Colloids and Surfaces A. 122:161-168.

[35] Chern C.S, Lin S.Y, Chang S.C, Lin J.Y, Lin Y.F (1998). Effect of Initiator on Styrene Emulsion Polymerisation Stabilised by Mixed SDS/NP-40 Surfactants. Polymer. 39:22812289.

[36] Javier I, Amalvy M.J, Unzué H.A.S, José M.A (2002) Reactive Surfactants in Heterophase Polymerization: Colloidal Properties, Film-Water Absorption and Surfactant Exudation. J. Polym. Sci. 40:2994-3000. 
[37] Guyot A, Tauer K, Asua J.M, Van S, Gauthier C, Hellgren A.C, Sherrington D.C, Goni A.M, Sjoberg M, Sindt O, Vidal F, Unzue M, Schoonbroad H, Shipper E, Desmazes P.L (1999) Reactive Surfactants in Heterophase Polymerization. Acta Polym. 50:57-66.

[38] Harkins W.D (1945) A General Theory of The Reaction Loci in Emulsion Polymerization. J. Chem. Phys. 13:381.

[39] Harkins W.D (1946) A General Theory of Reaction Loci in Emulsion Polymerization. J. Chem. Phys.14:47-48.

[40] Smith W and Ewart V (1948) Kinetics of Emulsion Polymerization. J. Chem. Phys. 16: 592-607.

[41] Available: en.wikipedia.org/wiki/Emulsion_polymerization.

[42] Gardon J. L (1968) Emulsion Polymerization I. Recalculation and Extension of SmithEwart Theory. J. Polym. Sci. A. 6:623-641.

[43] Priest W.J (1952) Particle Growth in the Aqueous Polymerization of Vinyl Acetate. J. Phys. Chem. 56:1077-1083.

[44] Roe C.P (1968) Surface Chemistry Aspects of Emulsion Polymerization. Ind. Eng. Chem. 60:20-33.

[45] Fitch R.M, Tsai C.H (1970) Polymer Colloids: Particle Formation in Nonmicellar Systems. Polym Lett. 8:703-710.

[46] Fitch R.M, Tsai C.H (1971) Particle Formation in Polymer Colloids. III. Prediction of the Number of Particles by Homogeneous Nucleation Theory. In: Fitch R.M editor. Polymer Colloids. Newyork: Plenum Press. pp. 73-102.

[47] Hansen F.K, Ugelstad J (1978) Particle Nucleation in Emulsion Polymerization. I. A Theory for Homogeneous Nucleation. J. Polym. Sci. A. 16:1953-1979.

[48] Alexander A.E (1962) Some Aspects of Emulsion Polymerization. J. Oil Colour Chem. Assoc. 45:12-15.

[49] Fitch R.M and Watson R.C (1979) Coagulation Kinetics in Polymer Colloids Determined by Light Scattering. J. Colloid İnterface Sci. 68:14-20.

[50] Feeney P.J, Geissler E, Gilbert R.G, Napper D.H (1988) SANS Study of Particle Nucleation in Emulsion Polymerization. J. Colloid İnterface Sci. 121:508-513.

[51] Hunkeler D, Candau F, Pichot C, Hemielec A.E, Xie T.Y, Barton J, Vaskova V, Guillot J, Dimoine M.V, Reichert K.H (1994) Heterophase Polymerizations: A Physical and Kinetic Comparison and Categorizarion. Adv. Polym. Sci. 112:115-133.

[52] Ugelstad J, El-Aasser M.S, Vanderhoff J.W (1973) J. Polym. Sci. Polym. Lett. 11: 503.

[53] Lopez de Arbina L and Asua J.M (1992) High-solids-Content Batch Miniemulsion Polymerization. Polym. 33: 4832-4837.

[54] Asua J.M (2002) Miniemulsion Polymerization. Prog. Polym. Sci. 27: 1283-1346.

[55] Vanderhoff J.W (1993) Recent Advances in the Preparation of Latexes. Chem. Eng. Sci. 48:203-217.

[56] Donescu D, Gosa K, Ciupitoiu A (1985) Semicontinuous Emulsion Polymerization of Vinyl Acetate. Part I. Homopolymerization with Poly(vinyl alcohol) and Nonionic Coemulsifier. J Macromol. Sci. Part A. 22:931-941. 
[57] Donescu D, Gosa K, Languri J and Ciupiţoiu A (1985) Semicontinuous Emulsion Polymerization of Vinyl Acetate. Part II. Copolymerization with Dibutyl Maleate J Macromol. Sci. Part A. 22:941.

[58] nuparek J, Bradna P, Mrkvickova L, Lednicky F, Quadrat O (1995) Effect of Initial Polymerization Conditions on the Structure of Ethyl Acrylate-Methacrylic Acid Copolymer Latex Particles. Collect. Czech. Chem. Commun. 60:1756-1764.

[59] Sajjadi S and Brooks B.W (1999) Semibatch Emulsion Polymerization of Butyl Acrylate. I. Effect of Monomer Distribution. J.Appl. Polym. Sci. 74:3094-3095.

[60] Sajjadi S and Brooks B.W (2000) Semibatch Emulsion Polymerization of Butyl Acrylate. II. Effects of Emulsifier Distribution. J.Appl. Polym. Sci. 79:582-584.

[61] Sajjadi S, Brooks B.W (2000) Semibatch Emulsion Polymerization Reactors: Polybutyl Acrylate Case Study. Chem. Eng. Sci. 55:4757-4781.

[62] Sajjadi S, Brooks B.W (2000) Unseeded Semibatch Emulsion Polymerization of Butyl Acrylate: Bimodal Particle Size Distribution. J. Polym. Sci.Part A. 38:528-545.

[63] Sajjadi S (2000) Particle Formation and Coagulation in the Seeded Semibatch Emulsion Polymerization of Butyl Acrylate. J. Polym. Sci. Part A. 38: 3612-3630.

[64] Sajjadi S (2001) Particle Formation Under Monomer-Starved Conditions in the Semibatch Emulsion Polymerization of Styrene. I. Experimental. J. Polym. Sci. Part A. 39:3940-3952.

[65] Al-Bagoury M, Yaacoub E.J (2003) Semicontinuous Emulsion Copolymerization of 3-Omethacryloyl-1,2:5,6-di-O-isopropylidene- $\alpha$-D-glucofuranose (3-MDG) and Butyl Acrylate (BA). Monomer Feed Addition. J.Appl. Polym.Sci. 90: 091-2102.

[66] Al-Bagoury M, Yaacoub E.J (2004) Semicontinuous Emulsion Copolymerization of 3-Omethacryloyl-1,2:5,6-di-O-isopropylidene- $\alpha$-D-glucofuranose (3-MDG) and Butyl Acrylate (BA) by Pre-emulsion Addition Technique. Europ. Polym. J. 40:2617-2627.

[67] Mayer M.J.J, Meuldijk J, Thoenes D (1994) Emulsion Polymerization in Various Reactor Types: Recipes with High Monomer Content. Chem. Eng. Sci. 49:4971-4980.

[68] Zhao K, Sun P, Liu D, Dai G (2004) The Formation Mechanism of Poly(vinyl acetate)/Poly(butyl acrylate) Core/Shell Latex in Two-satge Seeded Semi-continuous Starved Emulsion Polymerization. Europ. Polym. J. 40:89-96.

[69] im J.W, Suh K.D (2008) Monodisperse Polymer Particles Synthesized by Seeded Polymerization Techniques. J. Ind. Eng. Chem. 14:1-9.

[70] O’Donnell J.T, Mersobian R.B, Woodward A.E (1958) Vinyl Acetate Emulsion Polymerization. J. Polym. Sci. 28:171-177.

[71] French D.M (1958) Mechanism of Vinyl Acetate Emulsion Polymerization. J. Polym. Sci. 32: 395-411.

[72] Lindemann M.K (1967) Vinyl Polymrization. New York: Dekker. Vol 1. Pt 1. 260.

[73] Okaya T, Tanaka T, Yuki K (1993) Study on Physical Properties of Poly (vinyl acetate) Emulsion Films Obtained in Batchwise and in Semicontinuous Systems. J. Appl. Polym. Sci. 50:745.

[74] Gavat I, Dmonie V, Donescu D, Hagiopol C, Munteanu M, Gosa K and Deleanu T.H (1978) Grafting process in vinyl acetate polymerization in the presence of nonionic emulsifiers. J. Polym. Sci. Polym Symp. 64:125. 
[75] Gilmore C.M, Poehlin G.W, Schork F.J (1993) Modeling poly(vinyl alcohol)-stabilized vinyl acetate emulsion polymerization. I. Theory. J. Appl. Polym. Sci.48: 1449,1461.

[76] Gonzalez G.S.M, Dimonie V.L, Sudol, E.D, Yue H.J, Klein A, El-Aasser M.S (1996) Characterization of Poly(vinyl alcohol) During the Emulsion Polymerization of Vinyl Acetate Using Poly(vinyl alcohol) as Emulsifier. J. Polym. Sci. A: Polym. Chem. 34:849862.

[77] Suzuki A, Yano M, Saiga T, Kikuchi K, Okaya T (2003) Study on the Initial Stage of Emulsion Polymerization of Vinyl Acetate Using Poly(vinyl alcohol) as a Protective Colloid. Colloid Polym. Sci. 281:337-342.

[78] Carra S, Sliepcevich A, Canevarolo A and Carra S (2005) Grafting and Adsorption of Poly(vinyl) Alcohol in Vinyl Acetate Emulsion Polymerization. Polymer. 46:1379-1384.

[79] Chujo K, Harada Y, Tokuhara S, Tanaka, K (1969) The Effects of Various Monomer Addition Methods on the Emulsion Copolymerization of Vinyl Acetate and Butyl Acrylate. J. Polym. Sci. Part C. 27: 321-332.

[80] Misra S.C, Pichot C, El-Aasser M.S, VanderHoff, J.W (1979) Effect of Emulsion Polymerization Process on The Morphology of Vinyl Acetate-Butyl Acrylate Copolymer Lateks Films. J. Polym. Sci. Polym. Lett. Edd.17:567-572.

[81] Pichot C, Lauro M, Pham Q (1981) Microstructure of Vinyl Acetate-Butyl Acrylate Copolymers Studied by 13C-NMR Spectroscopy: Influence of Emulsion Polymerization Process J.Polym. Sci. Polym. Chem. Ed. 19:2619.

[82] El-Aasser M.S, Makgawınata T, VanderHoff, J.W (1983) Batch and Semicontinuous Emulsion Copolymerization of Vinyl Acetate-Butyl Acrylate. 1. Bulk, Surface and Colloidal Properties of Copolymer Latexes. J. Polym. Sci. 21:2363-2382.

[83] Sarac A, Berber H, Yıldırım H (2006) Semi-continuous Emulsion Copolymerization of Vinyl Acetate and Butyl Acrylate Using a New Protective Colloid. Part 2. Effects of monomer ratio and initiator. Polym. Adv. Technol. 17: 860-864.

[84] Berber H, Sarac A, Yıldırım H (2011) Synthesis and Characterization of Water-based Poly(vinyl acetate-co-butyl acrylate) Latexes Containing Oligomeric Protective Colloid. Polym. Bull. 66:881-892.

[85] Berber H, Sarac A, Yıldırım H (2011) A Comparative Study on Water-based Coatings Prepared in the Presence of Oligomeric and Conventional Protective Colloids. Prog. Org. Coat. 71:225-233.

[86] Erbil H.Y(1996) Surface Energetics of Films of Poly(vinyl acetate-butyl acrylate) Emulsion Copolymers. Polymer. 24:5483-5491.

[87] VanderHoff J.W (1985) Mechanism of Emulsion Polymerization. J.Polym. Sci. PolyM. Symp. 72:161-198.

[88] El-Aasser M.S, Makgawinata T, VanderHoff J.W (1983) Batch and Semicontinuous Emulsion Copolymerization of Vinyl Acetate-Butyl Acrylate. II. Morphological and Mechanical Properties of Copolymer Latex Films. J. Polym. Sci. 21:2383-2395.

[89] Dimitratos J, El-Aasser M.S, Georgakis C, Klein A (1990) Pseudosteady States in Semicontinuous Emulsion Copolymerization. J. Appl. Polym. Sci. 40:1005-1021. 
[90] Sun P.Q, Liu D.Z, Zhao K, Chen G.T (1998) Development of Particle Morphology Simulating of Emulsion Copolymerization of Vinyl Acetate and Butyl Acrylate. Acta Polym. Sinica. 5:542-548.

[91] Lazaridis N, Alexopoulos A.H, Kiparissides C (2001) Semi-batch Emulsion Copolymerization of Vinyl Acetate and Butyl Acrylate Using Oligomeric Nonionic Surfactants. Macromol.Chem.Phys. 202:2614-2622.

[92] Vandezande G.A, Rudin A (1992) In: Daniels E.D, Sudol E.D, El-Aasser M.S, editors. Polymer Latexes. Vol. 492. Washington: ACS Symp. Series. pp. 114.

[93] Vandezande G.A, Rudin A (1992) In: Daniels E.D, Sudol E.D, El-Aasser M.S, editors. Polymer Latexes. Vol.492. Washington: ACS Symp. Series. pp. 134.

[94] Delgado J, El-Aasser M.S, VanderHoff J.W (1986) Miniemulsion Copolymerization of Vinyl Acetate and Butyl Acrylate. I. Differences Between the Miniemulsion Copolymerization and The Emulsion Copolymerization Processes J. Polym. Sci. Polym.Chem. Ed. 24: 861-874.

[95] Wu, X.Q., Schork, F.J., (2000). "Batch and Semibatch Mini/Macroemulsion Copolymerization of Vinyl Acetate and Comonomers", Ind Eng Res. 39: 2855-2865.

[96] Brandrup J, Immergut E.H (1989). Polymer Handbook. New York: Wiley.

[97] Donescu D, Goşa K, Languri J (1990) Semicontinuous Emulsion Polymerization of Vinyl Acetate. VIII. Copolymerization with Di-2-ethylhexyl Maleate. Acta Polym. 41: 210-214.

[98] Donescu D, Fusulan L (1994) Semicontinuous Emulsion Polymerization of Vinyl Acetate X. Kinetics of Homopolymerizations, Copolymerizations, and Initiator Decomposition in the Presence of Sulfosuccinate-type Surfactants. 15:543-560.

[99] Berber H (2012) The Synthesis, Modification and Characterization of Nano-Sized Emulsion Polymers Using Functional Vinyl Monomers. Phd Thesis. İstanbul: Yildiz Technical University.

[100] Abad C, De La Cal J.C, Asua J.M (1995) Core-shell Structured Latex Particles. III. Structure-properties Relationship in Toughening of Polycarbonate with Poly $(n$-butyl acrylate)/Poly(benzyl methacrylate-styrene) Structured Latex Particles. J. Appl. Polym. Sci. 56:419-455.

[101] Donescu D, Fusulan L, Gosa K, Ciupitoiu A (1994) Semicontinuous Emulsion Polymerization of Vinyl Acetate. 12. Comopolymerization with Acid Monomers. Revue Roamanie de Chimie. 39:843-849.

[102] Garjria C, Vijayendran B.R (1983) Acid Distribution in Carboxylated Vinyl-Acrylic Latexes J. Appl. Polym. Sci. 28:1667-1676. 